PAULO JOSÉ LEONESI MALUF

PERMANÊNCIA E MUDANÇA CONSTITUCIONAL

Emendas constitucionais brasileiras

à luz do Direito Comparado.

Tese de Doutorado

Orientador: Professor Doutor José Levi Mello do Amaral Júnior

UNIVERSIDADE DE SÃO PAULO

FACULDADE DE DIREITO

SÃO PAULO-SP

2017 


\title{
PERMANÊNCIA E MUDANÇA CONSTITUCIONAL: EMENDAS CONSTITUCIONAIS BRASILEIRAS À LUZ DO DIREITO COMPARADO
}

Tese apresentada à Comissão Examinadora do Programa de Pós-Graduação stricto sensu da Faculdade de Direito da Universidade de São Paulo, como requisito parcial à obtenção do título de Doutor em Direito do Estado (área de concentração Direito Constitucional), sob orientação do Professor Doutor José Levi Mello do Amaral Júnior

\author{
UNIVERSIDADE DE SÃO PAULO \\ FACULDADE DE DIREITO \\ São Paulo \\ 2017
}




\section{Catalogação da Publicação \\ Serviço de Biblioteca e Documentação \\ Faculdade de Direito da Universidade de São Paulo}

MALUF, Paulo José Leonesi.

Permanência e Mudança Constitucional: Emendas Constitucionais brasileiras à luz do Direito Comparado / Paulo José Leonesi Maluf; orientador José Levi Mello do Amaral Júnior - São Paulo, 2017.

$230 \mathrm{f}$.

Tese (Doutorado - Programa de Pós-Graduação em Direito do Estado) Faculdade de Direito, Universidade de São Paulo, 2017.

1. Permanência e Mudança Constitucional. 2. Emendas Constitucionais Brasileiras. 3. Reforma Constitucional. 4. Constituição da República Federativa do Brasil de 1988. 5. Direito Constitucional Comparado.

I. Amaral Júnior, José Levi Mello do, orient. II. Permanência e Mudança Constitucional: Emendas Constitucionais brasileiras à luz do Direito Comparado. 


\section{FOLHA DE APROVAÇÃO}

Candidato: Paulo José Leonesi Maluf

PERMANÊNCIA E MUDANÇA CONSTITUCIONAL:

EMENDAS CONSTITUCIONAIS BRASILEIRAS

À LUZ DO DIREITO COMPARADO

Departamento de Direito do Estado

Banca Examinadora:

Prof. Dr.

Instituição:

Julgamento:

Assinatura:

Prof. Dr.

Instituição:

Julgamento:

Assinatura:

Prof. Dr.

Instituição:

Julgamento:

Assinatura:

Prof. Dr.

Instituição:

Julgamento:

Assinatura:

Prof. Dr.

Instituição:

Julgamento:

Assinatura:

São Paulo, de de 2017. 


\section{AGRADECIMENTOS E DEDICATÓRIA}

Ao Professor José Levi Mello do Amaral Junior, um Orientador no melhor sentido da palavra, pelo ensinamento preciso e pela conversa franca e amiga durante toda a orientação, exemplo, que tenho a ser seguido, de admirável conduta pessoal e profissional.

Ao Ministro Alexandre de Moraes, expoente de uma geração de constitucionalistas, meu Professor na Graduação e no Doutorado no Largo São Francisco, por me acolher em sua Assessoria no Ministério da Justiça e no Supremo Tribunal Federal.

Aos Professores Carlos Bastide Horbach e José Carlos Francisco, em especial pelos comentários, essenciais para a estruturação e para o desenvolvimento deste trabalho, no âmbito da elucidativa, gentil e profícua arguição do Exame de Qualificação.

Ao Professor Sérgio Antônio Ferreira Victor, pelas sugestões de leitura para o aperfeiçoamento de alguns pontos da pesquisa, quando o acompanhei nas aulas do Curso de Pós-Graduação em Direito Constitucional do Instituto de Direito Público de São Paulo.

Aos meus amigos de jornada de Doutorado, Renata Villela, Telma Lisowki, Eduardo Bucci, Paulo Fontes e Rodrigo Lobregat, pelo produtivo estímulo acadêmico compartilhado nas aulas e nas monitorias de nosso orientador nos últimos três anos.

Aos meus amigos da Procuradoria da Fazenda Nacional, do Ministério da Justiça e do Supremo Tribunal Federal, representados, respectivamente, pelo Estéfano G. Nonato, pelo Coronel Fernando de Lima Santos e pelo Rafael Koerig Gessinger, com quem muito aprendo, pessoal e profissionalmente, a cada dia de convivência e de trabalho.

Aos meus amigos, com especial menção ao Leandro Vilarinho, pela amizade fraternal e especificamente por alguns dos livros estrangeiros usados neste trabalho, com que me presenteou; ao Renato Tonelli, pelo incentivo e pelos comentários a este trabalho, e ao Vinícius Poli, companheiro de caminhada no Mestrado e no Doutorado no Largo São Francisco, pelas fundamentais sugestões para o desenvolvimento da tese.

Às minhas avós Maria e Nair, exemplos de doçura, firmeza e condução familiar, sempre presentes, mesmo à distância, em especial pelas inestimáveis orações.

À minha irmã Elisa, aos meus pais Angela e Paulo, à Ludmila, e a Deus, por serem tudo para mim e por estarem sempre comigo.

A todos agradeço e dedico, cordial e carinhosamente, este trabalho. 
"Malum est consilium quod mutari non potest." (Publilius Syrus, 85?-43? a. C) 


\section{RESUMO}

MALUF, Paulo José Leonesi. Permanência e Mudança Constitucional: Emendas Constitucionais brasileiras à luz do Direito Comparado. Tese de Doutorado. 230f. Faculdade de Direito da Universidade de São Paulo, 2017.

As emendas constitucionais representam um importante mecanismo de manutenção e adequação da ordem constitucional em um Estado Democrático de Direito. Conjuntamente com as limitações ao poder de alterar a constituição, revelam-se como estratégia de permanência e estabilidade do texto positivado, com a finalidade de conferir flexibilidade à constituição escrita, permitindo sua vigência para além do momento de criação. Buscam-se, com essa sistemática, estabilidade institucional, continuidade da ordem jurídica e plasticidade diante das transformações da sociedade. Por esta razão, convém que seu uso seja moderado. O que ocorre, porém, quando se depara com um cenário em que inúmeras políticas e medidas de governo são implementadas mediante emendas constitucionais, as quais passam a assumir tarefas e funções que, tradicionalmente, eram confiadas à legislação infraconstitucional? Trata-se do caso brasileiro, em que a profusão de emendas à Constituição de 1988 pode insinuar, ao menos em leitura superficial, que houve uma transformação profunda na estrutura do ordenamento constitucional brasileiro. Esse diagnóstico, contudo, requer uma análise que seja, ao mesmo tempo, mais abrangente, considerando um maior número de fatores de influência, e verticalizada, aprofundando-se a investigação. Afinal, não se pode deixar de reconhecer que o projeto constitucional de 1988 tem se mostrado altamente resiliente. Uma possível explicação - apresentada como tese ao longo deste trabalho - para a permanência do núcleo essencial da Constituição de 1988, não obstante o destacado número de emendas por que passou, consiste no fato de que seus dispositivos contendo temas materialmente constitucionais foram pouco alterados, tanto sob um critério quantitativo, como - o que é mais importante - sob uma perspectiva qualitativa. Para justificar a tese, são analisados os aspectos centrais da Teoria do Poder Constituinte e da Teoria da Constituição, bem como os fatores condicionantes de mudança e permanência constitucional. A partir desta análise, estudam-se as manifestações do poder constituinte reformador brasileiro desde a Constituição Imperial de 1824, à luz do Direito Constitucional Comparado, notadamente do poder constituinte reformador francês e do poder constituinte reformador italiano.

PALAVRAS-CHAVE: 1. Permanência e Mudança Constitucional. 2. Emendas Constitucionais. 3. Reforma Constitucional. 4. Constituição da República Federativa do Brasil de 1988. 5. Direito Constitucional Comparado. 


\begin{abstract}
MALUF, Paulo José Leonesi. Constitutional Endurance and Change: Brazilian Constitutional Amendments from the perspective of Comparative Law. Doctoral Dissertation. 230f. Faculdade de Direito da Universidade de São Paulo, 2017.
\end{abstract}

Constitutional amendments represent an important mechanism for maintenance and adaptation of the constitutional order under the Rule of Law. Together with the limitations on the power to alter the Constitution, they serve as a strategy to promote the continuity and stability of the existing text, in order to provide flexibility to the written constitution, allowing it to remain in effect after it has been drawn up. The purpose of this system is to ensure institutional stability, continuity of the legal order and plasticity in light of transformations in society. As a result, these mechanisms are best used in moderation. However, what happens under a scenario in which numerous government measures and policies are implemented through constitutional amendments, which begin to assume tasks and functions that had traditionally been entrusted to infra-constitutional legislation? This is the Brazilian case, in which the profusion of amendments to the 1988 Constitution could seem to suggest, at least from a superficial reading, that there was an indepth transformation of the structure of the Brazilian constitutional order. Nevertheless, such a diagnosis would require an analysis that is at the same time broader, considering a greater number of factors of influence, and more vertical, requiring a more in-depth investigation. After all, there is no question that the constitutional draft of 1988 has shown itself to be very resilient. One possible explanation, presented as a thesis over the course of this work, for the continuity of the essential core of the 1988 Constitution, in spite of the high number of amendments it underwent, consists of the fact that its provisions containing materially constitutional topics were altered very little, both from a quantitative standpoint, and, more importantly, from a qualitative perspective. To justify this thesis, the central aspects of the Theory of Constituent Power and of the Theory of the Constitution are analyzed, as are the conditioning factors of constitutional change and continuity. Based on this analysis, the manifestations of Brazilian constitutional reform are studied from the Imperial Constitution of 1824 , based on Comparative Constitutional Law, notably the French constitutional reforming power and the Italian constitutional reforming power.

KEY WORDS: 1. Constitutional Endurance and Change. 2. Constitutional Amendments.

3. Constitutional Reform. 4. Constitution of the Federative Republic of Brazil of 1988.

5. Comparative Constitutional Law. 


\section{RIASSUNTO}

MALUF, Paulo José Leonesi. Permanenza e Cambiamento Costituzionale: Emendamenti Costituzionali brasiliani in base al Diritto Comparato. Tesi di Dottorato. 230f. Faculdade de Direito da Universidade de São Paulo, 2017.

Gli emendamenti costituzionali sono un meccanismo importante per la conservazione e l'adeguamento dell'ordine costituzionale in uno Stato Democratico di Diritto. Unitamente alle limitazioni del potere di modificare la Costituzione, si mostrano come una strategia di permanenza e stabilità del testo ratificato, allo scopo di concedere flessibilità alla costituzione scritta, e di che la sua validità vada oltre alla fase di elaborazione. Mediante tale modalità si ricerca la stabilità istituzionale, la continuità dell'ordine giuridico e l'elasticità di fronte alle trasformazioni della società. Per tale ragione è importante che il suo utilizzo sia moderato. Quando invece si trova di fronte uno scenario in cui innumerevoli politiche e misure del governo sono attuate mediante emendamenti costituzionali, che assumono incombenze e funzioni che, per tradizione, erano affidate alla legislazione infracostituzionale? È il caso brasiliano, in cui la profusione di emendamenti alla Costituzione del 1988 può suggerire, almeno superficialmente, che vi è stata una trasformazione profonda nella struttura dell'ordinamento costituzionale brasiliano. Tale constatazione richiede tuttavia un'analisi più esaustiva e un'indagine approfondita, tenendo conto di un maggior numero di fattori d'influenza e verticalizzata. Infine non si può non riconoscere che il progetto costituzionale del 1988 si è mostrato estremamente resiliente. Una spiegazione possibile presentata come tesi nel corso del presente lavoro - per la permanenza del nucleo essenziale della Costituzione del 1988, nonostante il numero considerevole di emendamenti attuati, consiste nel fatto che i relativi dispositivi contenenti temi materialmente costituzionali sono stati poco modificati, sia dal punto di vista quantitativo, sia - e cosa più importante - dalla prospettiva qualitativa. Per dimostrare la tesi, si esaminano gli aspetti centrali della Teoria del Potere Costituente e della Teoria della Costituzione, nonché i fattori condizionanti del cambiamento e della permanenza costituzionale. Da questa analisi, si esaminano le manifestazioni del potere costituente riformatore brasiliano, dalla Costituzione Imperiale del 1824, in base al Diritto Costituzionale Comparato, in particolare del potere costituente riformatore francese e del potere costituente riformatore italiano.

PAROLE-CHIAVE: 1. Permanenza e Cambiamento Costituzionale. 2. Emendamenti Costituzionali. 3. Riforma Costituzionale. 4. Costituzione della Repubblica Federativa del Brasile del 1988. 5. Diritto Costituzionale Comparato. 


\section{CAPÍTULO 1 - PODER CONSTITUINTE, CONSTITUIÇÃO E MODIFICAÇÃo

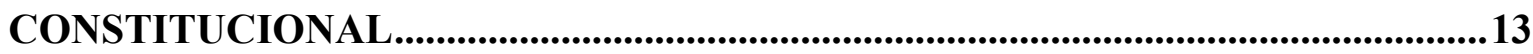

1.1. A gênese e a evolução da constituição: poder constituinte originário e poder constituinte instituído

1.1.1. A gênese da constituição e o poder constituinte originário 14

1.1.2. A evolução da constituição e o poder constituinte instituído

1.1.3. As manifestações do poder constituinte instituído: revisão, reforma e emenda ....23

1.2. O significado, a forma e o conteúdo da constituição .28

1.2.1. "Constituição": delimitação de um termo polissêmico 28

1.2.2. Constituição em sentido formal 34

1.2.3. Constituição em sentido material. 39

1.3. A alterabilidade, o conteúdo e as funções da constituição. .47

1.3.1. Constituições rígidas e constituições flexíveis 47

1.3.2. As funções da constituição. 51

1.3.3. O conteúdo e as funções da constituição sob a perspectiva da Ciência Política: polity, policy e politics 
2.1.1. Considerações iniciais. 63

2.1.2. O debate entre Thomas Jefferson e James Madison a propósito da longevidade das constituições. 65

2.1.3. Permanência e mudança constitucional: entre estabilidade e longevidade 70

2.2. Fatores de permanência e mudança constitucional relativos à gênese e à estrutura

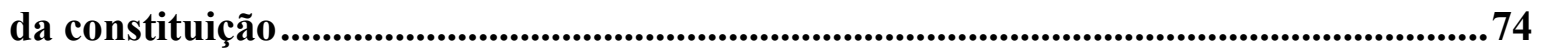

2.2.1. Contexto no momento histórico de formação das constituições............................. 76

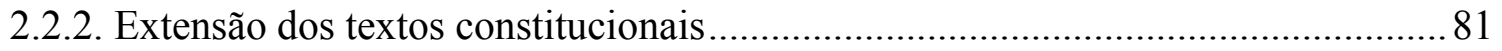

2.2.3. Mecanismos adotados para a modificacão das constituições .................................84

2.3. Fatores de permanência e mudança constitucional relativos ao ambiente em torno

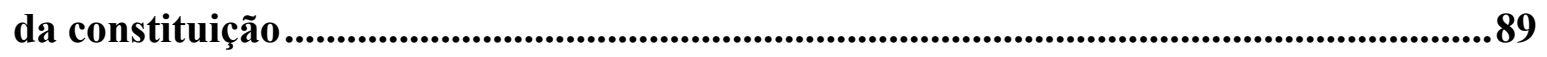

2.3.1. Estabilidade política, econômica e social. .......................................................... 89

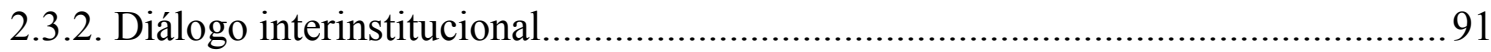

2.3.3. Perdurabilidade ou longevidade constitucional .................................................... 95

2.4. Síntese conclusiva: quantas emendas constitucionais são emendas demais? ........97 
3.2. A primeira Constituição brasileira - Constituição Politica do Imperio do Brazil, de 25 de março de 1824 102

3.3. A primeira Constituição republicana brasileira - Constituição da República dos Estados Unidos do Brasil, de 24 de fevereiro de 1891 105

3.4. A Constituição efêmera - Constituição da República dos Estados Unidos do Brasil, de 16 de julho de 1934 109

3.5. A Constituição do Estado Novo - Constituição da República dos Estados Unidos do Brasil, de 10 de novembro de 1937 .112

3.6. A Constituição da quarta república brasileira - Constituição da República dos Estados Unidos do Brasil, de 18 de setembro de 1946 115

3.7. As Cartas de 1967 e 1969 - Constituição da República Federativa do Brasil de 24 de janeiro de 1967 e Emenda Constitucional n. 1, de 17 de outubro de 1969 120

3.8. A Constituição-cidadã - Constituição da República Federativa do Brasil de 1988 
CAPÍtUlo 4 - PERMANÊNCIA E MUdANÇA CONSTITUCIONAL À LUZ DO DIREITO COMPARADO .148

4.1. O Direito Comparado na pesquisa jurídica e no estudo específico do Direito

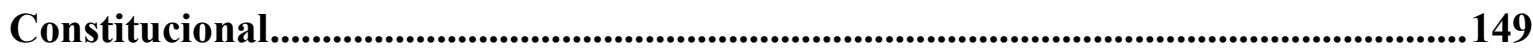

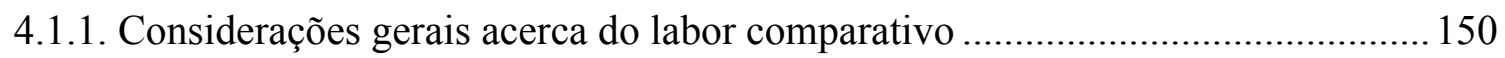

4.1.2. Comparação jurídica em geral e Direito Comparado ........................................ 151

4.1.3. Comparação jurídico-constitucional e Direito Constitucional Comparado .......... 156

4.2. O poder constituinte reformador francês ...............................................................162

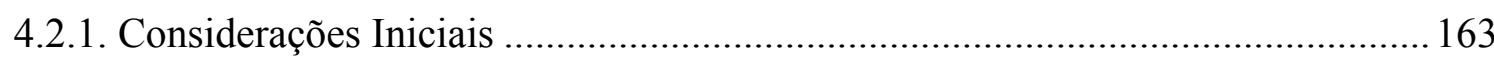

4.2.2. Caracterização da Constituição Francesa da Quinta República (1958) ................ 166

4.2.3. O procedimento de reforma na Constituição Francesa de 1958 .......................... 171

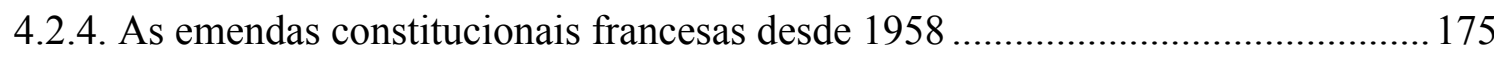

4.3. O poder constituinte reformador italiano......................................................182

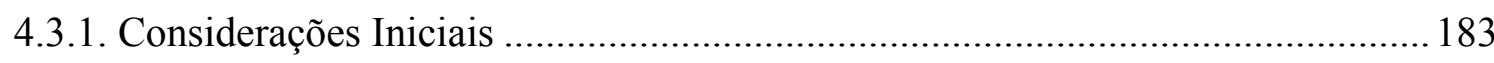

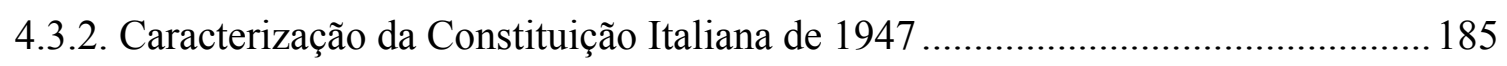

4.3.3. O procedimento de reforma na Constituição Italiana de 1947 ............................ 188

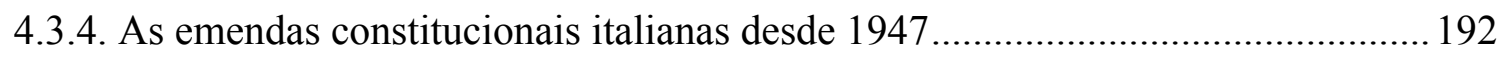

4.4. Análise comparativa das manifestações dos poderes constituintes reformadores

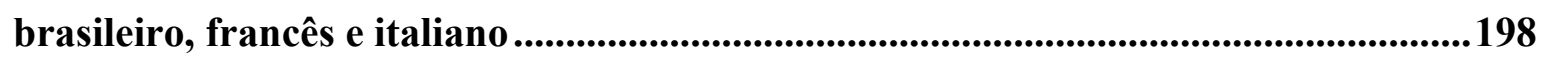

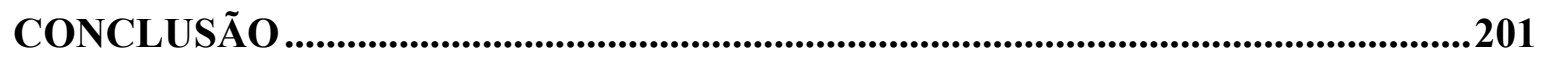

REFERÊNCIAS BIBLIOGRÁFICAS..................................................................211 


\section{INTRODUÇÃO}

Inspirada na célebre obra “O que é o terceiro estado?”, do abade EmmanuelJoseph Sieyès, a doutrina constitucionalista clássica tradicionalmente subdivide o poder constituinte em poder constituinte originário e poder constituinte instituído.

De modo introdutório, tem-se que originário é o poder de elaborar uma nova constituição, em um momento de ruptura com a ordem jurídica anterior. Trata-se de poder político permanente, marcado pela ilimitação jurídico-material e pela incondicionalidade procedimental. Instituído, por outro lado, é o poder constituinte de modificação constitucional, ao qual se atribui a tarefa de atualização da ordem constitucional, em especial por meio de alterações formais empreendidas no contexto do processo legislativo. Trata-se de poder juridicamente subordinado ao poder constituinte originário.

De acordo com esta classificação tradicional, a distinção entre poder constituinte originário e poder constituinte instituído é, portanto, de natureza - são poderes com características e dimensões distintas. Enquanto o poder originário situa-se, eminentemente, no domínio da política, em que a soberania é exercida com o objetivo de criar ou refundar o Estado e a ordem jurídica, o poder instituído é um poder de ação, delimitado e regulado, essencialmente, por normas jurídicas já positivadas.

O processo formal de modificação das normas constitucionais, realizado no exercício do poder constituinte instituído, pode ser levado a efeito por diversas formas. No âmbito do direito brasileiro, o poder constituinte instituído reformador é exercitado, sobretudo, por meio das emendas à constituição - objeto central do estudo proposto.

Previstas no corpo permanente do texto da Constituição da República Federativa do Brasil de 1988 como principal veículo formal de manifestação do poder constituinte reformador, as emendas constitucionais têm por objetivo - de forma singela possibilitar a permanente atualização do ordenamento constitucional.

O poder de emendar a constituição está demarcado por um quadro de limitações de forma - que compreendem os limites circunstanciais, procedimentais e temporais - e de conteúdo, que restringem o modo pelo qual determinadas matérias podem ser objeto de modificação. 
A definição de tais limitações, conjugada com a previsão das emendas constitucionais, revela-se como estratégia de permanência e estabilidade do texto positivado, com a finalidade de conferir flexibilidade à constituição escrita, permitindo sua vigência para além do momento de criação. Buscam-se, com essa sistemática, estabilidade institucional, continuidade da ordem jurídica e plasticidade diante das transformações da sociedade.

Sob essa perspectiva, as emendas constitucionais representam um importante mecanismo de manutenção e de adequação da ordem constitucional em um Estado Democrático de Direito. Por esta razão, convém que seja moderado o seu uso.

Com efeito, uma vez que a estabilidade está diretamente relacionada à aplicabilidade e à eficácia da constituição, a constante alteração constitucional, se abundante e desarrazoada, pode afigurar-se danosa à "força normativa da constituição"1 e ao estabelecimento e à manutenção de um "sentimento constitucional"2.

Essa preocupação com a imoderação no exercício do poder constituinte reformador ganha relevo ao se considerar o caso brasileiro. Isso porque é significativa a frequência com que a Constituição da República de 1988 tem sido alterada.

Foram promulgadas, até o presente momento, contando com as seis emendas de revisão, um total de cento e uma emendas constitucionais ${ }^{3}$. Detalhando-se tal informação sob um prisma quantitativo, constata-se que, nestes 28 anos de vigência da Constituição de 1988, mais da metade de seus artigos (193, ou 51,6\% de um total de 378 artigos) já foram, em maior ou menor grau, alterados, inseridos ou suprimidos por emendas.

\footnotetext{
${ }^{1}$ Dessa forma, cada alteração constitucional pode expressar "a ideia de que, efetiva ou aparentemente, atribuise maior valor às exigências de índole fática do que à ordem normativa vigente". HESSE, Konrad. A Força Normativa da Constituição. [Tradução de Gilmar Ferreira Mendes]. Porto Alegre: Sérgio Antônio Fabris, 1991, p. 22 ss.

${ }^{2}$ Sobre o "sentimento constitucional", cf. LOEWENSTEIN, Teoría de la Constitución. 2. ed. Barcelona: Ariel, 1979, p. 199-200. Destaca-se um pequeno trecho: "Una constitución es tanto mejor cuanto con más facilidad pueden efectuarse cambios en la estructura social sin modificación de la mecánica del proceso politico. Las reformas constitucionales son absolutamente imprescindibles como adaptaciones de la dinámica constitucional a las condiciones sociales en constante cambio; pero cada una de ellas es una intervención, (...), y debe ser solamente efectuada con gran cuidado y extremada reserva. (...) toda reforma constitucional, aunque sea de naturaleza puramente técnica y no afecte en absoluto a los intereses del pueblo propiamente dichos, significa una depreciación de lo que se podría designar como el sentimiento constitucional de un pueblo." Cf., também, SUNSTEIN, Cass; HOLMES, Stephen. "The politics of constitutional revision in Eastern Europe". In: LEVINSON, Sanford. Responding to imperfection: The theory and practice of constitutional amendment. New Jersey: Princeton University Press, 1995, p. 302: "The rational reason for a subsequent generation to respect the terms of the constitutional settlement, in any case, has less to do with the source than with the content of the constitution. If a constitution does not help current citizens to solve their problems and achieve their aims, it will and should have little appeal (...). The appropriateness of treating a constitution as "sacred" surely depends on what the constitution contains. Thus, respect for the constitution must be based on the public perception that the constitution is (still at least generally) good".

${ }^{3}$ A mais recente, a Emenda Constitucional n. 95, foi promulgada em 15 de dezembro de 2016.
} 
O título "Da organização do Estado" teve 21 artigos alterados (77\% do total de 27 artigos); o título "Dos direitos e garantias fundamentais", 8 artigos alterados (61,5\% do total de 13); o título "Da Tributação e do Orçamento", 16 artigos alterados (59,2\% do total de 27); o título "Da Ordem Social”, 24 artigos alterados (55,8\% do total de 43); o título "Da organização dos Poderes", 52 artigos alterados (54,1\% do total de 96); o Ato das Disposições Constitucionais Transitórias, 55 artigos alterados ou inseridos (46,6\% de 118); o título "Das disposições gerais", 8 artigos alterados (44\% do total de 18); o título "Da Ordem Econômica e Financeira", 7 artigos alterados (30,4\% do total de 23); o título "Da Defesa do Estado e das Instituições Democráticas”, 2 artigos alterados (22\% do total de 9); apenas o título "Dos Princípios Fundamentais" não passou por alteração alguma. ${ }^{4}$

Sob um prisma qualitativo, observam-se modificações da Constituição em áreas muito diversas entre si. É possível verificar, por exemplo, a regulação de políticas públicas no âmbito de setores sensíveis, como a prestação de serviços de gás canalizado (Emenda n. 5/95), a exploração de recursos minerais e potenciais de energia hidráulica (Emenda n. 6/95), a navegação de cabotagem e interior (Emenda n. 7/95), serviços de telefonia e telecomunicação (Emenda n. 8/95), atividades relacionadas ao petróleo e ao gás natural (Emenda n. 9/95), ensino (Emenda n. 14/96), e Sistema Financeiro Nacional (Emenda n. 40/2003). Vislumbra-se, também, uma reorientação política da atuação do Estado em diversas áreas, a exemplo da educação básica (Emendas n. 14/1996 e n. 59/2009), da saúde pública (Emendas n. 29/2000 e 51/2006) e do desenvolvimento cultural (Emendas n. $48 / 2005$ e n. $71 / 2012$ ).

Isso sem contar redefinições mais extensas, verdadeiras reformas, promovidas no regime constitucional do Poder Judiciário (Emenda n. 45/2004), da Seguridade Social (Emendas n. 20/98, n. 41/2003, n. 47/2005, n. 88/2015) e das finanças públicas, especialmente em relação ao financiamento de políticas sociais e econômicas (Emendas n. 3/93, n. 10/96, n. 12/96, n. 14/96, n. 17/97, n. 21/99, n. 27/2000, n. 33/2001).

\footnotetext{
${ }^{4}$ Trata-se de levantamento feito por este autor. Em outra análise quantitativa, tendo por base informações que se referem ao período de 25 anos a contar da promulgação da Constituição de 1988, publicou-se, em outubro de 2013, que "a Constituição chega aos 25 anos 39\% maior do que quando foi promulgada, em 1988. Levantamento obtido pelo GLOBO revela que, desde a primeira emenda constitucional, em 1992, até a Emenda n. 73, de junho passado, foram acrescidos 718 dispositivos e retirados 80 do texto original, que já contava com 1.627 dispositivos. O saldo, de 638 dispositivos, mostra como a Carta não para de crescer”. In: O GLOBO. Texto atual é 39\% maior do que o aprovado em 1988. Segunda-feira, 30 de setembro de 2013.
} 
É necessário considerar também a candente necessidade de muitas reformas a serem empreendidas no corpo da Constituição de 1988, ainda por se fazer, como, por exemplo, as reformas política, eleitoral e tributária, o que inevitavelmente resultará na produção de um número igualmente considerável de novas emendas constitucionais. ${ }^{5}$

Depara-se, então, com um cenário em que inúmeras políticas e medidas de governo são implementadas mediante emendas constitucionais, as quais passam a assumir tarefas e funções que, tradicionalmente, eram confiadas à legislação infraconstitucional. Consequentemente, a profusão de emendas à Constituição de 1988 pode insinuar, ao menos em leitura superficial, que houve uma transformação profunda na estrutura do ordenamento constitucional brasileiro.

Esse diagnóstico, porém, requer uma análise que seja, ao mesmo tempo, mais abrangente, considerando um maior número de fatores de influência, e verticalizada, aprofundando-se a investigação. Afinal, não se pode deixar de reconhecer que "o projeto constitucional de 1988 tem se mostrado altamente resiliente"

Uma possível explicação - apresentada como tese ao longo deste trabalho para a permanência do núcleo essencial da Constituição de 1988, não obstante o destacado número de emendas por que passou, consiste no fato de que seus dispositivos contendo temas materialmente constitucionais foram pouco alterados, tanto sob um critério quantitativo, como - o que é mais importante - sob uma perspectiva qualitativa.

\footnotetext{
${ }^{5}$ Nesse sentido, AMARAL JÚNIOR, José Levi Mello do. 20 Anos da Constituição Brasileira de 1988: a Constituição foi capaz de limitar o poder? In: MORAES, Alexandre de (Coord.). Os 20 anos da Constituição da República Federativa do Brasil. São Paulo: Atlas, 2009, p. 133, pondera que "Com vistas a maior (e melhor) limitação constitucional do poder, vale cogitar (ou insistir sobre) três reformas institucionais, quais sejam: (1) adoção do voto distrital; (2) separação entre Chefia de Estado e Chefia de Governo; (3) transformação do Supremo Tribunal Federal em típico tribunal constitucional. As duas primeiras podem ser compreendidas enquanto dois estágios do aprendizado e do amadurecimento democráticos. A terceira, uma complementação para aperfeiçoamento da jurisdição constitucional, em benefício da democracia".

${ }^{6}$ Com efeito, a Constituição da República Federativa do Brasil de 1988 “não apenas manteve estável o sistema político brasileiro, como tem sido capaz de atualizar-se e adaptar-se às necessidades políticas e econômicas sem, com isso, deixar de realizar incrementalmente sua forte ambição normativa". Além disso, "a resiliência textual, associada ao consensualismo político, tem contribuído para que o processo político possa constantemente atualizar um texto extensamente ambicioso, mas razoavelmente fácil de ser reformado. Essa resiliência textual, no entanto, não autorizou que elementos centrais de nossa arquitetura constitucional fossem alterados(...). Do ponto de vista da história política, a detalhista e ambiciosa Constituição brasileira se mostrou capaz de assimilar mudanças de rumo determinadas por consensos políticos consistentes, sem perder sua identidade. Viabiliza a sua reforma para a adaptação de novas situações, mas impede que elementos básicos do pacto constitucional sejam abandonados. Essa resiliência textual contribuiu para garantir a estabilidade do pacto político conciliador e a paulatina realização das promessas constitucionais de longo prazo". DIMOULIS, Dimitri (Org.). Resiliência constitucional: compromisso maximizador, consensualismo político e desenvolvimento gradual. São Paulo: Direito GV, 2013, p. 7 e p. 23-24.
} 
Considerando tudo o que foi até aqui exposto, e para que seja possível estruturar uma fundamentação em torno desta hipótese principal de trabalho, as questões principais a serem analisadas estarão encadeadas com o objetivo de embasar a resposta ao principal questionamento a ser enfrentado com o desenvolvimento da tese: a Constituição da República Federativa do Brasil de 1988 foi, de fato, consideravelmente modificada, como faz supor o elevado número de emendas por que passou?

Esta é a indagação central a que se busca responder com a elaboração da tese, servindo de fio condutor para a resolução de outras questões também relevantes, apresentadas a seguir, seguindo-se a ordem em que serão tratadas ao longo dos quatro capítulos que compõem o presente trabalho investigativo.

Qual é o conceito material substantivo de constituição? Para responder a tal indagação, cumpre realizar, ainda que brevemente, um estudo da literatura clássica sobre o Poder Constituinte e sobre a Teoria da Constituição, com o objetivo de se apontar um conceito substantivo de constituição, a servir de parâmetro para se analisar se efetivamente os temas materialmente constitucionais presentes na Constituição da República Federativa do Brasil de 1988 foram significativamente alterados.

Um ponto de partida - notável - para as investigações a serem empreendidas é o conteúdo do artigo 16 da Declaração dos Direitos do Homem e do Cidadão, de 1789 "A sociedade em que não esteja assegurada a garantia dos direitos nem estabelecida a separação dos poderes não tem Constituição"7 .

Contudo, embora se reconheça a inegável importância desse referencial teórico, sobre o qual se alicerçou a doutrina constitucionalista clássica para conformar o conceito material de constituição, a análise proposta a ele não poderá se limitar.

Com efeito, também devem ser ponderadas, em caráter complementar, as funções desempenhadas, contemporaneamente, por um texto constitucional em uma sociedade complexa, bem como devem ser levadas em consideração as relações existentes entre o Direito Constitucional e a Ciência Política, ponto do qual se extrairão subsídios das consequências da relevante diferenciação conceitual entre polity, policy e politics.

Disso se cuidará no Capítulo 1.

\footnotetext{
${ }^{7}$ No original: "Toute Société dans laquelle la garantie des Droits n'est pas assurée, ni la séparation des Pouvoirs déterminée, n'a point de Constitution".
} 
Em um segundo momento, caberá uma análise dos principais fatores condicionantes de mudança e permanência constitucional, existentes e atuantes tanto nas etapas de sua formação, como posteriormente, ao longo da existência da constituição, com o objetivo de responder às duas questões seguintes:

Quais os principais fatores condicionantes da permanência e da mudança constitucional relativos à gênese e à estrutura da constituição? Parece-nos que existem alguns parâmetros - além daqueles já abordados no capítulo inicial - que podem servir de guia para se procurar uma resposta: (i) como é sua caracterização quanto à sua extensão?, (ii) qual é a sua longevidade?, (iii) qual é o impacto do contexto histórico no momento de sua formação?, (iv) como é a mecânica de modificação formal da constituição?

Quais os principais fatores condicionantes da permanência e da mudança constitucional que atuam ao longo da existência da constituição? Além dos parâmetros acima mencionados, igualmente válidos para esta análise voltada a um momento posterior à gênese constitucional, é importante considerar, na medida em que a constituição é, por excelência, o instrumento de regulação da vida política de uma sociedade, que mudanças, sejam elas sociais, políticas, culturais ou econômicas, são fatores que normalmente conduzem à necessidade de alterações constitucionais.

Parece aceitável afirmar que fatores referentes à interpretação constitucional e ao sistema de controle de constitucionalidade guardam importante relação com a quantidade de emendas. Nesse sentido, processos informais de alteração constitucional são de relevo e devem ser considerados, ainda que não sejam objeto específico de estudo - este é, aliás, um importante recorte de caráter metodológico adotado no presente trabalho.

Tendo percorrido este caminho, intentar-se-á responder a mais um questionamento importante para a estruturação e desenvolvimento da tese: "Quantas emendas constitucionais são emendas demais?" 8

\footnotetext{
${ }^{8}$ Esta questão foi título de uma palestra de Dieter Grimm, Professor da Universidade Humboldt de Berlim, e ex-Presidente do Tribunal Constitucional Alemão, realizada na manhã do dia 22 de maio de 2013, na Sala da Congregação da Faculdade de Direito do Largo São Francisco, da Universidade de São Paulo. Nela se discorreu sobre a quantidade de emendas constitucionais em alguns ordenamentos jurídicos, notadamente Brasil e Alemanha. Destacando alguns pontos exemplificativos, mencionou-se que a constituição brasileira é dez vezes maior que a alemã, apesar de ser quarenta anos mais nova, circunstância que pode relativizar os números. A constituição indiana, por sua vez, é tão antiga quanto a germânica, mas quatro vezes mais longa, o que justificaria a maior quantidade de emendas. A Constituição Espanhola de 1978, por sua vez, sofreu apenas duas alterações, uma em 1992, por força do Tratado de Maastricht, e outra em 2011, acerca da estabilidade orçamentária das regiões autônomas. A Constituição dos Estados Unidos, com seus quase duzentos e trinta anos, foi emendada apenas vinte e sete vezes. A constituição japonesa também apresenta uma característica
} 
Ainda que em uma análise preliminar, parece plausível afirmar que a mera quantidade de emendas constitucionais existentes em um determinado ordenamento jurídico-constitucional não se afigura, por si só, como critério satisfatório para responder a esta questão. Nesse sentido, não basta verificar a quantidade, estritamente em números absolutos, de emendas constitucionais, em diferentes Estados, como, por exemplo, Alemanha, Brasil, Espanha, Estados Unidos, Índia, Itália, França e Portugal.

Além disso, eventualmente, uma só emenda pode provocar uma ampla modificação constitucional ${ }^{9}$, com a alteração de diversos e significativos dispositivos constitucionais, distribuídos em inúmeros artigos diferentes, ao passo que outras várias emendas podem alterar, ao longo de vários anos, um único dispositivo ${ }^{10}$.

Parece razoável afirmar, ademais, que dez emendas constitucionais de caráter inclusivo, de ampliação de direitos e garantias fundamentais, sejam desejáveis e profícuas, assim como parece igualmente verossível o argumento de que uma só emenda restritiva, ou que traga incerteza e insegurança jurídica, seja deletéria e indesejável.

Esses pontos serão tratados, portanto, no Capítulo 2.

Em seguida, será feita análise de cada um dos textos constitucionais brasileiros desde a Constituição Imperial de 1824. Serão enfocados, em relação a cada uma das constituições, (i) sua caracterização geral - apontando o que se adotou como forma de Estado e como forma, sistema e regime de governo; (ii) seu tempo de vigência; (iii) o número total de emendas por que passou; e (iv) os dispositivos constitucionais regulatórios do procedimento de alteração formal. Na sequência, proceder-se-á a um levantamento sistemático de todas as emendas constitucionais que alteraram cada uma das Constituições.

Cumprida esta etapa, objetiva-se realizar uma síntese conclusiva, em que serão realçados os elementos característicos do poder constituinte reformador brasileiro, consistindo em análise comparativa diacrônica ${ }^{11}$.

Esse será, pois, o objeto do Capítulo 3.

muito incomum: apesar de permitir que emendas sejam feitas facilmente, não foi alterada - uma possível explicação, dada por Grimm, é a cultura dos japoneses, que consideram desrespeitoso alterar as leis.

${ }^{9}$ A Emenda Constitucional n. 45/2004, por exemplo, alterou ou incluiu dispositivos em mais de trinta artigos: os artigos $5^{\circ}, 36,52,92,93,95,98,99,102,103,104,105,107,109,111,112,114,115,125,126,127,128$, 129, 134 e 168 foram alterados, e os artigos 103-A, 103-B, 111-A e 130-A foram acrescentados.

${ }^{10}$ Exemplo disso é o artigo 100 da Constituição de 1988, que foi alterado pelas Emendas Constitucionais n. 20/98, 30/2000, 37/2002, 62/2009 e 94/2016.

${ }^{11}$ A distinção entre análise comparativa diacrônica e análise comparativa sincrônica será apresentada em tópico específico-item 4.1.2. 
Por fim, em virtude de parecer-nos coerente o argumento de que a análise proposta ganha amplitude, profundidade e adequação ao se valer das contribuições de um estudo feito à luz do Direito Comparado, discorrer-se-á, sinteticamente, sobre os fundamentos do labor jurídico-comparativo, em geral, do Direito Comparado, em particular, e do Direito Constitucional Comparado, mais especificamente.

Em um passo seguinte, serão estudados os principais contornos e manifestações do poder constituinte reformador francês e italiano sobre, respectivamente, a Constituição Francesa da Quinta República, de 1958 e a Constituição Italiana de $1947^{12}$. Realizada esta tarefa, empreender-se-á, a título de arremate, uma análise comparativa das manifestações dos poderes constituintes reformadores brasileiro, francês e italiano.

Trata-se, portanto, do conteúdo do Capítulo 4.

Apresentado, de forma sintética, este panorama, cumpre apresentar breves considerações sobre a justificativa da escolha do tema, sua importância e a contribuição original, que se propõe com a pesquisa, à ciência jurídica brasileira.

Considero que a primeira locução do título acima - justificativa da escolha tem o claro condão de se misturar com a segunda - importância do tema. Parece razoável e coerente que, em uma atividade científica, a justificativa da escolha do tema se dê primordialmente por sua importância. Evidentemente que nem sempre isto acontece. Porém, no caso proposto, é possível afirmar que sim.

O desejo de avançar uma investigação científica, de cunho acadêmico mais aprofundado, em torno da problemática das emendas constitucionais no Direito brasileiro, surgiu durante os estudos realizados ao longo do curso de Mestrado.

Com efeito, o ponto de partida de minha dissertação intitulada "Conselho Nacional de Justiça: análise de sua competência disciplinar" foi a significativa alteração da Constituição de 1988 levada a efeito pela Emenda Constitucional n. 45, de 2004.

\footnotetext{
${ }^{12}$ A justificativa para a escolha das vigentes constituições francesas e italianas como parâmetro de comparação com o ordenamento constitucional brasileiro serão apresentadas, em capítulo próprio, adiante - itens 4.2.1. $e$ 4.3.1. De todo modo, já nesta Introdução uma observação deve ser registrada. Não se pode olvidar que, no âmbito das ciências jurídicas, em especial em um estudo acadêmico de doutoramento, a utilização de análise comparatística enseja cuidados especiais. Uma pesquisa que se propõe a ser feita à luz do Direito Comparado inadmite a importação ou a transposição acrítica de situações, fenômenos e institutos jurídicos de um sistema jurídico para outro. Por esta razão, deve ser cuidadosa a escolha dos sistemas ou ordenamentos jurídicos a servirem de análise comparativa, não podendo ser muitos, sob pena de se incorrer em provável superficialidade, nem tão diferentes, pois deve haver um mínimo de similaridade entre os elementos de comparação.
} 
Naquele momento, vislumbrou-se, no plano do poder constituinte reformador no Direito brasileiro, um campo muito fértil para pesquisa acadêmica. Esta percepção renovava-se constantemente com a frequente edição de novas emendas constitucionais.

A escolha pautou-se também outra razão especial. Objetivou-se estudar um tema que se preocupasse, sobremaneira, com problemas constitucionais atuais e que estivessem relacionados, diretamente, às peculiaridades da sociedade contemporânea. Um tema que, embora predominantemente jurídico, com acentuado viés teórico, não se mostrasse desconectado da realidade. ${ }^{13}$

O tema proposto se mostra relevante porque se situa em um plano em que se intersectam os importantes campos (i) da teoria do constitucionalismo ${ }^{14}$, (ii) da organização dos Poderes em um Estado Democrático de Direito e (iii) dos direitos e garantias fundamentais ${ }^{15}$, cujo conhecimento é indispensável para a construção de uma base teórica sólida, que possibilite o desenvolvimento de futuros trabalhos científicos. Com efeito, estando na origem da formação da ordem jurídica, quando se evidenciam os seus fundamentos axiológicos, o poder constituinte - e a forma de compreendê-lo - repercute em vários aspectos do Direito Constitucional ${ }^{16}$, permitindo reanálises e reinterpretações.

13 Tanto é assim que o tema também tem sido objeto de recentes debates científicos. Apenas exemplificativamente, mencionam-se: (1) No exterior, simpósio que ocorreu em janeiro de 2014 em Nova York, promovido pela American Association of Law Schools, intitulado "Comparative Constitutional Change: New Perspectives on Formal and Informal Amendment”. Dele participaram, dentre outros, os professores Mark Tushnet (Harvard Law School), Richard Albert (Boston College Law School), Joel Colon-Rios (Victoria University of Wellington), Thomas Ginsburg (University of Chicago), Vicki Jackson (Harvard University), David Landau (Florida State University), Sanford Levinson (University of Texas), Kim Lane Scheppele (Princeton University), Rosalind Dixon (University of New South Wales), Ran Hirschl (University of Toronto). (2) No Brasil, simpósio que se realizou, em setembro de 2016, na Universidade de Brasília - "Global Symposium on Constitutional Amendment and Replacement in Latin America".

${ }^{14}$ Sobre o ponto, discorrem SAJÓ, András. Limiting Government: An Introduction to Constitutionalism. Budapest: Central European University, 1999, p. 39 - "No matter how technical it may seen, amending a constitution is an essential element of the document itself and of constitutionalism" - e BOYRON, Sophie. "France". In: How constitutions change. A comparative study. Oxford and Portland: Hart Publishing, 2013, p. 115 - "the regulation of constitutional change is at the heart of the doctrine of constitutionalism. Indeed, in most constitutional systems, the process by which constitutional norms change will determine fundamental questions for the regime such as survival, efficiency and legitimacy. (...) a close analysis of the manner in which a constitutional system evolves often reveals the deep nature and specific characteristics of that system."

${ }^{15}$ No constitucionalismo moderno, a autoridade da constituição emana de sua fonte popular, fenômeno que o vincula diretamente às organizações democráticas do poder. Cf., nesse sentido, PREUSS, Ulrich K. "The exercise of constituent power in Central and Eastern Europe". In: WALKER, Neil; LOUGHLIN, Martin. The Paradox of Constitutionalism: Constituent Power and Constitutional Form. Oxford: Oxford University Press, 2007, p. 212.

${ }^{16}$ Nesse sentido, CAMPOS, Juliana Cristine Diniz. "Nomogênese e Poder Constituinte: fundamentação racional e a legitimidade democrática da norma constitucional". Tese de Doutoramento apresentada à Faculdade de Direito da Universidade de São Paulo, 2013, destaca, por exemplo, os temas (i) da suposição de normas constitucionais inconstitucionais, (ii) dos limites do poder de reforma constitucional e (iii) do direito adquirido em face de ordem constitucional superveniente. 
O estudo sobre a permanência e a modificação das constituições relaciona-se diretamente, de acordo com Jon Elster, com o próprio desenvolvimento do constitucionalismo moderno e com a Teoria da Constituição, na medida em que a opção pelo modelo de reforma implica escolhas, no campo da política constitucional, entre maior flexibilidade ou rigidez constitucional, entre maior estabilidade ou maior abertura a mudanças. Implica, ademais, o estabelecimento de limitações - materiais, circunstanciais, temporais - e de procedimentos formais, mais ou menos rigorosos, com quóruns mais ou menos elevados e, naqueles Estados que adotam a forma federativa, implica escolhas entre a maior ou menor participação dos entes federativos no processo de reforma ${ }^{17}$.

Elucida também a relevância da temática a percepção de que a história constitucional dos Estados ocidentais modernos é uma história de mudanças. Inúmeras cartas constitucionais foram produzidas, violadas, extintas, recriadas. A sociedade mundial e os problemas jurídicos tornaram-se maiores e mais complexos, por vezes transbordando as fronteiras estatais, o que demanda respostas mais estruturadas e abrangentes.

Com a proposta de exame do poder constituinte reformador brasileiro à luz do Direito Comparado, criam-se aportes teóricos originais que podem auxiliar o debate sobre a compreensão da essência da constituição, da gênese das normas constitucionais e de suas repercussões para uma interpretação e um entendimento sistêmicos do ordenamento jurídico.

Essa possibilidade de contribuição para o debate científico é especialmente relevante ao se constatar uma escassez, no Brasil, de estudos específicos dedicados ao tema do poder constituinte reformador brasileiro, elaborados por meio de uma sistematização, com enfoque acadêmico predominantemente jurídico, à luz do Direito Comparado. ${ }^{18}$

\footnotetext{
${ }^{17}$ Segundo Jon Elster, a maior ou menor dificuldade para se emendar um texto constitucional pode representar uma diferente perspectiva de constituição, se estrutura ou se instrumento para a ação: "the procedures for revising the constitution are closely connected with the general spirit of constitutionalism. The more difficult is to change the constitution, the more people tend to view it as a given framework for action rather than as an instrument for action. Of course, the people may also come to see it as an insupportable prison, thus there is a need for an optimal degree of rigidity of the constitution". ELSTER, Jon. "Constitutionalism in Eastern Europe: an introduction". University of Chicago Law Review, n. 58, 1991, p. 470-471.

${ }^{18}$ Antes do advento da Constituição de 1988, Manoel Gonçalves Ferreira Filho já apontava que "a literatura científica não é fértil em estudos sobre a estabilidade e a continuidade da Constituição. Na verdade, raros são os trabalhos de ciência política que abordam, mesmo de viés, o tema. E raríssimos os juristas que com ele se preocuparam, sequer de passagem, em suas obras". FERREIRA FILHO, Manoel Gonçalves. Estabilidade e continuidade da Constituição. In: Idéias para a nova Constituição brasileira. São Paulo: Saraiva, 1987, p. 22. Também Nelson Saldanha, em texto produzido para um concurso de livre docência antes da promulgação da Constituição de 1988, analisa o poder constituinte objetivando conciliar o universalismo de uma proposta teórica abstrata com a observação da experiência histórica, e afirma que se trata de tema "tão árduo e complexo quanto fundamental e sugestivo", ainda que pouco estudado na bibliografia nacional. SALDANHA, Nelson. O Poder Constituinte. São Paulo: Revista dos Tribunais, 1986.
} 
A literatura jurídica brasileira raramente cuida, de forma minuciosa, do tratamento da atuação do poder constituinte reformador no âmbito de outros ordenamentos jurídicos, e quando o faz, não há uma sistematização própria de Direito Comparado, revelando-se como uma apresentação, por vezes mais sucinta, por vezes mais detalhada, de um panorama da situação em outras constituições. ${ }^{19}$

$\mathrm{Na}$ literatura jurídica estrangeira, apesar de serem proporcionalmente mais frequentes do que em nosso país, também não se encontram muitos estudos científicos detidos sobre o tema. ${ }^{20}$

O estudo proposto pretende, pois, deslocar o eixo analítico mais comum, na doutrina brasileira, sobre o tema do poder constituinte reformador, consistente, de forma geral, em exames mais voltados à sua natureza, às suas espécies, às suas limitações, ocasionalmente com ênfase nos aspectos quantitativos, superficialmente apontando para a alta frequência de produção de emendas constitucionais no Brasil.

Essa nova perspectiva é possível porque se propõe uma análise eminentemente jurídica das emendas constitucionais brasileiras à luz do Direito Comparado. Trata-se, ressalte-se, de uma análise comparatística - mas não de mera comparação por justaposição - de alguns aspectos teóricos do poder constituinte reformador, com o objetivo de formar um substrato teórico apto a fomentar o estudo da constante elaboração de emendas à Constituição da República Federativa do Brasil de 1988.

\footnotetext{
${ }^{19}$ Nesse sentido, citem-se, por exemplo: (1) FRANCISCO, José Carlos. Emendas Constitucionais e limites flexíveis. Rio de Janeiro: Forense, 2003, p. 137-146; (2) LOPES, Maurício Antonio Ribeiro. Poder Constituinte Reformador: limites e possibilidades da revisão constitucional brasileira. São Paulo: Revista dos Tribunais, 1993, p. 202-238; (3) AYRES BRITTO, Carlos. "O Regime Jurídico das Emendas à Constituição". Tese de Doutorado apresentada à Faculdade de Direito da Pontifícia Universidade Católica de São Paulo, 1999; (4) SILVA, José Afonso. Um pouco de Direito Constitucional Comparado. Três projetos de Constituição. São Paulo: Malheiros, 2009; (5) VALLE, Vanice Lírio do. Transição política e construtivismo constitucional: uma análise empírica das emendas constitucionais brasileiras. In: CAMARGO, Margarida Maria Lacombe; LOIS, Cecilia Caballero; MARQUES, Gabriel Lima (Org.) Democracia e jurisdição: novas configurações constitucionais brasileiras. Rio de Janeiro: Imo`s Gráfica e Editora, 2013. No campo da Sociologia Política, destaca-se o trabalho de Cláudio Couto e Rogério Arantes: COUTO, Cláudio Gonçalves; ARANTES, Rogério Bastos. Constituição, governo e democracia no Brasil. In: Revista Brasileira de Ciências Sociais, v. 21, n. 61, junho de 2006.

${ }^{20}$ Apenas para ilustrar o argumento: (1) DORSEN, Norman; ROSENFELD, Michel; SAJÓ, András; BAER, Susanne. Comparative Constitutionalism, p. 89-92; (2) LOEWENSTEIN, Teoría de la Constitución. 2. ed. Barcelona: Ariel, 1979, p. 160-205 passim; (3) MIRANDA, Jorge. Manual de Direito Constitucional. Tomo II. 6. ed. Coimbra: Coimbra Editora, 2007, p. 184-190; e (4) SAJÓ, András. Limiting Government: An Introducion to Constitutionalism. Budapest: Central European University, 1999, p. 40-42. Três obras recentes que avançam mais na problemática em tela são: (1) ELKINS, Zachkary; GINSBURG, Tom; MELTON, James. The endurance of national constitutions. New York: Cambridge, 2009; (2) OLIVER, Dawn; FUSARO, Carlo. How constitutions change. A comparative study. Oxford/Portland: Hart Publishing, 2013 e (3) CONTIADES, Xenophon. (Org.) Engineering Constitutional Change: A Comparative Perspective on Europe, Canada and USA. London and New York: Routledge, 2012.
} 
O deslocamento proposto deve-se, também, à sistematização com que se pretende analisar a temática. Com o objetivo de fundamentar a tese formulada - o conteúdo materialmente constitucional da Constituição de 1988 foi sensivelmente menos alterado do que faz supor o simples número de emendas constitucionais até hoje promulgadas pretende-se partir do estudo da Teoria da Constituição e do Poder Constituinte e analisar os principais fatores condicionantes da mudança e da permanência constitucional.

$$
\text { Interessa-me, enfrentando criticamente as divergências e as }
$$
complementaridades de diferentes perspectivas - sem incorrer em uma postura eclética lançar novas luzes ao tratamento tradicional dado ao tema do poder constituinte reformador no Direito Brasileiro. Objetiva-se, com isso, trazer novos elementos que provoquem um debate mais extenso e mais profundo sobre o tema e sobre questões a ele relacionadas.

Ao fim e ao cabo, o tema justifica-se e mostra-se importante na medida em que a análise das alterações formais realizadas em uma determinada constituição possibilita a formulação de uma apreciação de cunho jurídico abrangente do respectivo ordenamento jurídico. $^{21}$ Justifica-se, também, pelo esforço a ser empreendido para uma melhor compreensão tanto da Teoria da Constituição como do poder constituinte reformador brasileiro, com a finalidade de fornecer subsídios para o desenvolvimento jurídico do país. E, seu estudo, por meio da sistematização proposta, e à luz do Direito Comparado, parece apto a prestar uma contribuição original à ciência jurídica brasileira. ${ }^{22}$

\footnotetext{
${ }^{21}$ Nesse sentido, se a Constituição "é a culminação natural de uma revolução bem-sucedida", então "pode dizer-se que a revolução só foi bem-sucedida depois de os momentos estabilizadores propiciados pelas diversas revisões terem garantido a consolidação e persistência democráticas". Desta forma, "só a constituição revista revela as constâncias e mutações de uma identidade constitucional": In: CANOTILHO, José Joaquim G. Direito Constitucional e Teoria da Constituição. 7. ed. Coimbra: Almedina, 2003, p. 214.

${ }^{22}$ Cumpre, por fim, apresentar uma nota metodológica. O tratamento do método no âmbito das investigações jurídico-científicas deve ter como pressuposto a necessária distinção entre método de trabalho e abordagem metodológica. Sob o primeiro significado, costumam-se apontar os acervos bibliográficos a serem consultados e utilizados. Nesse sentido, no estudo proposto, o método de trabalho consistirá na análise da doutrina especializada nacional e estrangeira - a indicação bibliográfica preliminar está ao fim deste Plano de Pesquisa - bem como das normas jurídicas concernentes ao tema proposto.Quanto à abordagem metodológica, a pesquisa terá caráter jurídico-dogmático, em suas três vertentes: analítica, pela análise dos conceitos envolvidos e da relação entre eles; empírica, pelo estudo da produção normativa pelo legislador constituinte reformador brasileiro e de outros ordenamentos jurídicos; e normativa, na medida em que pretende apresentar respostas em face das questões a serem enfrentadas. Neste sentido, valendo-se de Robert Alexy, Martin Borowski e Friedrich Müller, SILVA, Virgílio Afonso da. Direitos Fundamentais: Conteúdo Essencial, Restrições e Eficácia. São Paulo: Malheiros, 2009, p. 30.
} 


\section{CONCLUSÃO}

O objetivo desta singela conclusão não é - nem poderia ser - apresentar elementos novos, diferentes daqueles já delineados ao longo do trabalho. Por esta razão, serão apresentadas nótulas referentes aos principais tópicos estruturantes da tese. Ao término desta súmula, ponderações de caráter geral serão formuladas.

1. A noção de poder constituinte é, a um só tempo, suporte lógico da ideia de constituição e justificativa de sua superioridade. A constituição, por sua vez, por derivar daquele poder, não pode ser livremente modificada pelos poderes constituídos, os quais são obra do poder constituinte por intermédio da própria constituição. O poder constituinte originário, de caráter inegavelmente político - um poder supra legem ou legibus solutus - é aquele que impõe, a partir de um dado momento e em um certo espaço, os comandos, os objetivos e os valores que uma determinada comunidade seguirá.

2. O poder de alteração da constituição - um poder constituinte instituído - é normalmente disciplinado pelo próprio texto constitucional produzido pelo constituinte originário, que lhe impõe obediência a regras e parâmetros condicionantes. Embora pertinentes considerações doutrinárias apontem para a razoabilidade de se empregar a terminologia "competências" ou "faculdades", justifica-se a utilização da expressão "poder constituinte instituído", na medida em que dele decorre a produção de normas de caráter constitucional. Uma de suas manifestações mais evidentes - e mais frequentes - é a produção de emendas, destinadas ao aperfeiçoamento do texto constitucional.

3. São variadas as manifestações do poder constituinte instituído. Considerando que tanto o legislador constituinte, brasileiro e estrangeiro, quanto a literatura jurídica, não utilizam, de modo sistemático e uniforme, os termos "reforma", "emenda" e “revisão constitucional”, é relevante diferenciá-las. Para os fins adotados neste trabalho, tem-se, à luz do sistema constitucional brasileiro, que reforma constitucional lato sensu é toda alteração formal que modifica o texto constitucional, instrumentalizada por emendas constitucionais, sejam elas ordinárias, sejam elas emendas de revisão - neste caso quando houver um elemento de programação periódica. Já em sentido estrito, considera-se que reforma constitucional é o resultado da alteração da Constituição, levada a efeito por emendas, que se revele mais substanciosa, tanto sob uma perspectiva quantitativa - alteração mais extensa - como sob um prisma qualitativo - alteração mais profunda. 
4. O termo "constituição" é polissêmico. Sua utilização, seja em âmbito jurídico, seja na seara coloquial, comporta inúmeras variações. Deve-se compreender o conceito de constituição como uma construção cultural e, por esse motivo, um dado temporal e espacialmente situado. O termo apresenta tanto uma acepção dinâmica, de "ação de constituir", como uma acepção estática, de "composição resultante desta ação". De um ponto de vista mais amplo, constituição é toda a composição do ser. Mais estritamente, é a base ou a parte essencial de uma organização. Para os propósitos deste trabalho, parte-se da ideia de que a constituição é um conjunto jurídico-normativo sistematizado, que forma a cúpula da ordem estabelecida, que tem por objeto a organização política basilar de um Estado, e por finalidade a limitação do poder, para a preservação dos direitos fundamentais das pessoas.

5.1. A distinção entre constituição em sentido material e constituição em sentido formal - ou, sob outro enfoque, entre normas apenas materialmente constitucionais e normas apenas formalmente constitucionais - é utilizada comumente na literatura jurídica.

5.2. O que caracteriza uma norma como sendo formalmente constitucional, não é, obviamente, um determinado conteúdo, mas o modo de sua elaboração e o meio pelo qual é veiculada. Portanto, uma constituição em sentido formal assim se caracteriza por ter forma constitucional e por ter sido elaborada como tal mediante um processo legislativo especial, mais qualificado e dificultoso, diferenciado do processo legislativo ordinário.

5.3. O marco teórico simbolizado pelo conteúdo do artigo 16 da Declaração Universal dos Direitos do Homem e do Cidadão, de 1789, deve ser recuperado e enfatizado, mas a ele não se pode ficar restrito quando se está diante da tarefa de apontar o conteúdo e o sentido material de constituição que se mostrem mais consentâneos com uma contemporânea Teoria da Constituição, adequada ao atual estágio evolutivo da sociedade e do constitucionalismo. Trata-se, em razão disso, de um importante ponto de partida. Devese, portanto, ir além. A concepção de constituição material que se adotou no presente trabalho é aquela que considera por materialmente constitucionais os temas da forma de Estado, da forma de governo, do sistema de governo e do regime de governo, o que contempla uma interpretação ampliativa da estruturação basilar da organização e do funcionamento dos poderes constituídos e o resguardo dos direitos e garantias fundamentais. Para essa conclusão confluem os entendimentos, colacionados em tópico próprio, de Karl Loewenstein, Carl Schmitt, Georg Jellinek, Giovanni Sartori, Paolo Biscaretti di Ruffìa, Jorge Miranda, José Joaquim Gomes Canotilho e Manoel Gonçalves Ferreira Filho. 
6. A contraposição entre rigidez e flexibilidade constitucional, formulada inicialmente por James Bryce e Albert Dicey, tem por critério de diferenciação o respeito à estabilidade do texto constitucional, no sentido do maior ou menor grau de dificuldade no tocante à alteração constitucional. Por esse critério, é rígida a constituição que, para ser alterada, exige a observância de uma forma específica, distinta daquela seguida para a elaboração das leis ordinárias. É flexível aquela em que não se estremam o processo legislativo ordinário e o processo legislativo de alteração constitucional.

7. Uma análise das emendas constitucionais brasileiras a partir de um parâmetro estrutural de constituição, considerando-se tanto seu sentido formal como seu sentido material, ganha sustentação e alcance se for complementada por um parâmetro funcional. Se, por um lado, as constituições se desincumbem de inúmeras funções diferentes, cuja importância é variável, espacial e temporalmente, conforme o contexto histórico em que se situem, por outro lado, não convém, em um levantamento de um rol de funções de uma constituição, que se aspire à completude, sobretudo por ser raro encontrar exata correspondência entre um rol geral e um rol específico de funções efetivamente desempenhadas por uma dada ordem constitucional. De todo modo, pode-se identificar um núcleo de funções essenciais, aptas a serem consideradas comuns ao geral das constituições, consistente nas funções de ordenação, organização, estruturação, limitação jurídica e controle do poder, bem como de reconhecimento e garantia dos direitos fundamentais.

8. O Direito Constitucional e a Política são indissociáveis. Afinal, a constituição, escrita ou não, consubstancia um conjunto de instituições que dão identidade ao regime político, estabelecendo e limitando os poderes dos governos, fornecendo os princípios para a disputa política e determinando a relação entre as pessoas e o Estado. Por esse motivo, a constituição, além de ser um produto da política, é também a política em seu aspecto formal - polity - e estabelece os atores, regras, objetivos, procedimentos e limites em que o jogo político - politics - ocorrerá para a produção de políticas públicas - policies. Diferentes análises das emendas à Constituição brasileira de 1988, empreendidas, sob a perspectiva da Ciência Política, por diferentes cientistas políticos brasileiros - Cláudio Couto, Rogério Arantes, Celina Souza e Marcus André Melo - apontam para uma mesma direção: a grande quantidade de dispositivos particularistas e controversos contidos no texto, sobretudo em matéria de policies, permite entrever tanto um cenário de indefinição e provisoriedade no contexto da elaboração e promulgação da Constituição de 1988, como uma abertura a um cenário de significativa frequência de emendamento constitucional. 
9.1. As constituições, em sua grande maioria, pretendem-se definitivas, sem duração prefixada, mas raramente, mesmo com esse intuito, impõem-se como imodificáveis. As constituições operam no tempo, objetivando regular o futuro, com fundamento na experiência e nas condições do presente em que é elaborada. Para operar no tempo, requerem, pois, capacidade de perdurar. Como consequência natural desse fato, nenhuma constituição que vigore por um período mais ou menos longo deixará de sofrer modificações.

9.2. Mais relevante que a mera longevidade constitucional, é a estabilidade da ordem constitucional. Esta, porém, não significa imutabilidade. Ao contrário, a estabilidade de uma Constituição pressupõe a sua capacidade de ininterruptamente adaptarse às novas situações advindas das modificações na sociedade. Desenvolveram-se, por isso, mecanismos destinados a adaptar o texto constitucional às novas demandas sociais, como é o caso das emendas constitucionais e da mutação constitucional. Assim, a longevidade pretendida pelas constituições tem mais afinidade com a estabilidade, produto de uma relação dialética entre permanência e mudança, do que propriamente com a imutabilidade.

10. O debate entre Thomas Jefferson e James Madison a propósito da longevidade das constituições é bastante conhecido e reiteradamente referido na literatura político-constitucional. Esses dois importantes pais fundadores norte-americanos sustentaram diferentes pontos de vista acerca da duração das constituições. Em termos gerais, Jefferson pregava a necessidade de substituição da constituição, de tempos em tempos, ao passo que Madison era defensor de sua máxima continuidade. De acordo com uma simples contagem, a história mostra um claro veredito: Madison estava certo; Jefferson, errado. Afinal, na maioria de suas disposições fundamentais, a Constituição dos Estados Unidos permanece a mesma desde que foi elaborada. No entanto, em análise mais aprofundada, pode-se dizer que Jefferson teve sua "vingança", não por meio de alterações formais, mas por práticas sociais e interpretações que remodelaram a Constituição norteamericana, tornando-a muito diferente daquela elaborada pelos Founding Fathers.

11.1. A análise da permanência e mudança de uma constituição pode ser atribuída a vários fatores, os quais, por sua vez, podem ser elencados em dois conjuntos: fatores relativos à gênese e à estrutura da constituição - fatores de design - e fatores relativos ao ambiente em torno da constituição - fatores de environment. A distinção gênese/estrutura versus ambiente, ou "design" versus "environment", assemelha-se à diferenciação clássica no campo da biologia entre "nature", um dado relativamente fixo para um determinado organismo vivo, e "nurture", que pode variar quase que infinitamente. 
11.2. Dentre os fatores de design, foram analisados o contexto no momento histórico de formação das constituições, a extensão dos textos constitucionais e os mecanismos adotados para a modificação das constituições. Dentre os fatores de environment, analiram-se a estabilidade política, econômica e social, o diálogo interstitucional e a perdurabilidade constitucional.

11.3. Mesmo com a vasta amplitude do rol de condicionantes, sejam elas de design, sejam elas de environment, e mesmo considerando a grande complexidade subjacente a este quadro, bem assim das peculiaridades de cada uma delas, em cada ordenamento constitucional, as quais não podem ser desprezadas, parece inequívoco apontar que o padrão de emendamento constitucional em um determinado ordenamento jurídico está diretamente relacionado com tais fatores, que se apresentam-se como aptos a influenciar, em maior ou menor grau, a mudança e a permanência constitucional.

12. Assim como a definição dos fatores condicionantes da permanência e mudança constitucional não é uma tarefa fácil ou simplesmente intuitiva, como foi apontado, o questionamento "quantas emendas constitucionais são emendas demais?" só pode ser considerado de simples solução se for possível formular uma resposta igualmente simples "depende". Em análise mais atenta, depara-se com uma pergunta relativamente complexa. Como questões complexas exigem respostas por múltiplas aproximações, vários fatores devem ser considerados. Em linhas gerais, concluiu-se que a quantificação numérica de emendas constitucionais não expressa necessariamente o quanto uma determinada constituição foi significativametne alterada. De outro modo, a frequência de emendamento deve ser considerada um indicativo frágil da magnitude de mudança constitucional. Basta mencionar, sob uma perspectiva quantitativa, que uma emenda de grande extensão pode afetar o conteúdo da constituição tanto ou mais que dez emendas menores.

13.1. A “Constituição Politica do Imperio do Brazil”, de 25 de março de 1824, vigorou por sessenta e cinco anos e sofreu uma única emenda, praticada pelo Ato Adicional de 1834, posteriormente interpretado pela Lei n. 105, de 12 de maio de 1840, o que não significou uma alteração substancial no sistema constitucional positivo.

13.2. A Constituição da República de 24 de fevereiro de 1891, embora tenha sido emendada apenas uma vez, por meio da Emenda n. 1, de 1926, teve alterados alguns temas constitucionais sensíveis, todos em sua parte material, a exemplo da intervenção federal nos Estados, do veto presidencial e dos direitos e garantias fundamentais, sem implicar, contudo, substancial modificação no sistema constitucional da Primeira República. 
13.3. A Constituição da República de 16 de julho de 1934 teve o mais curto período de vigência da história constitucional brasileira, o que dificulta uma análise empírica mais acurada acerca de sua alterabilidade. Não obstante essa circunstância, em apenas uma ocasião a Constituição foi formalmente modificada, por meio do Decreto Legislativo n. 6, de 18 de dezembro de 1935, mediante o qual foram publicadas três emendas à Constituição, sendo que apenas a primeira delas versou sobre assunto tipicamente material, o que não teve o condão de significar uma alteração substancial no sistema constitucional positivo.

13.4. A Constituição da República de 11 de novembro de 1937 foi alterada por vinte e uma Leis Constitucionais. Embora algumas das delas tenham alterado dispositivos referentes a matéria tipicamente constitucional - caso das Leis Constitucionais n. $1,3,4,7,10,11,14$ e 16 - tais modificações foram pontuais. A única que realmente teve um grande impacto foi a Lei Constitucional n. 9, de 28 de fevereiro de 1945, que modificou trinta e seis artigos, versando sobre temas constitucionais sensíveis.

13.5. A Constituição da República dos Estados Unidos do Brasil de 18 de setembro de 1946 vigorou por vinte e um anos e, durante este período, foi modificada por um total de vinte e uma emendas constitucionais, das quais apenas três podem ser consideradas realmente mais relevantes - as Emendas n. 4, 6 e 9. As demais, ainda que tenham tocado em temas importantes, como matéria eleitoral, tributária, orçamentária e funcionamento da Administração Pública, não tiveram grande impacto transformador, do que se conclui que não houve substanciosa modificação do sistema constitucional positivo.

13.6. A Constituição da República de 24 de janeiro de 1967 vigorou por vinte e um anos e foi modificada por um total de vinte e sete emendas. Não foi preservada de alterações significativas, e a primeira delas, a Emenda Constitucional n. 1, de 17 de outubro de 1969, é bastante ilustrativa deste fato. As alterações empreendidas pelas emendas à Constituição de 1967 foram substanciais, não apenas pelo teor materialmente constitucional, como pela extensão e profundidade com que modificaram o sistema constitucional vigente.

13.7. A Constituição da República Federativa do Brasil de 5 de outubro de 1988 foi objeto, até o momento, de cento e uma emendas à Constituição de 1988, considerando-se as seis emendas de revisão. De todas elas, apenas trinta e nove trataram de temas que podem ser considerados materialmente constitucionais, sendo que somente doze promoveram uma alteração mais significativa da estrutura constitucional brasileira de 1988 . Com isso, a partir da premissa segundo a qual se consideram materialmente constitucionais os temas da forma de Estado, da forma de governo, do sistema de governo e do regime de 
governo, o que contempla uma interpretação ampliativa da estruturação basilar da organização e funcionamento dos poderes e do resguardo dos direitos e garantias fundamentais, e em face da análise feita ao longo deste tópico, comprova-se a tese de que o conteúdo material da Constituição brasileira de 1988 foi sensivelmente menos modificado do que o simples número de emendas constitucionais promulgadas faz supor.

14.1. O Direito Comparado na acepção de comparação de direitos vai além da atividade ordinária, muitas vezes cotidiana, dos operadores do Direito, que constantemente precisam justapor, cotejar e harmonizar normas de seus próprios ordenamentos jurídicos, comparando-as, de modo refletido, seja antes de adotar decisões práticas, seja antes de formular conclusões teóricas. O Direito Comparado pressupõe uma dimensão extra, que é o elemento de internacionalidade e/ou de intertemporalidade.

14.2. O Direito Comparado não se confunde com o simples conhecimento do direito estrangeiro. Distingue-se pela utilização do método comparativo e pela apresentação de conclusões - a chamada síntese comparativa. Por essa razão, é incorreto denominar, como Direito Comparado, a mera justaposição de informações sobre diferentes ordens jurídicas ou sobre o regime jurídico de institutos jurídicos afins em diferentes ordens jurídicas.

14.3. A comparação diacrônica - comparação no tempo ou vertical - coteja elementos que se sucedem no tempo, imediatamente ou não, num mesmo espaço. A comparação sincrônica - comparação no espaço ou horizontal - confronta elementos de ordens jurídicas da mesma época, mas de lugares diferentes. É diacrônica a comparação entre o poder constituinte reformador manifestado ao longo das diferentes constituições brasileiras - Capítulo 3. É sincrônica, de outro lado, a comparação entre os poderes constituintes reformadores brasileiro, francês e italiano, relativamente às respectivas Constituições vigentes - Capítulo 4.

15.1. A França apresenta uma fortíssima tradição no que diz respeito à modificação constitucional. Passou por diversas e muito relevantes transformações constitucionais, experimentando diferentes formas, regimes e sistemas de governos, sendo palco de golpes e de revoluções, culminando com a adoção de um total de quinze constituições escritas. Essa circunstância parace apta a fundamentar a assertiva de que a França consubstancia-se como um verdadeiro "laboratório de análise de mudanças constitucionais", a justificar sua escolha como parâmetro de comparação. 
15.2. A Constituição de 1958 inseriu uma nova cultura de modificação do texto constitucional na França, o que antes era tido como exceção. Se antes se preferia mudar de Constituição a mudar $a$ Constituição, o panorama agora é outro. Com efeito, desde 1958, a Constituição francesa foi emendada, por meio das chamadas “lois constitutionnelles", vinte e quatro vezes, com uma frequência crescente. Foram apenas cinco emendas durante os primeiros três decênios de existência, ao passo que se elaboraram treze emendas entre os anos de 1998 e 2008, quando ocorreu a última alteração formal, em que se promoveu uma vastíssima - em extensão e em profundidade - reforma constitucional.

15.3. O número crescente e aceleração na frequência dos emendamentos não significam, contudo, uma banalização do procedimento de alteração ou um enfraquecimento do texto fundamental. Ao contrário, esta capacidade de adaptação, que contrasta com a imobilidade que tinham demostrado as constituições francesas anteriores, aparece como um indispensável elemento de flexibilidade para a evolução da Constituição francesa de 1958.

15.4. Das vinte e quatro emendas constitucionais francesas - Lois Constitutionnelles - que alteraram textualmente a Constituição de 1958, apenas uma, a Lei Constitucional n. 96-138, de 22 de fevereiro de 1996, que versou sobre a votação, pelo Parlamento, de leis de financiamento da seguridade social, não modificou tema considerado materialmente constitucional. Todas as demais vinte e três leis constitucionais afetaram a constituição em sentido material.

16.1. A Itália tem uma história constitucional composta por menos textos constitucionais positivados - quatro - do que o Brasil e a França. No entanto, justificam sua escolha, como parâmetro comparativo, a inserção no mesmo grande sistema jurídico da Civil Law, a relativa aproximação contextual, com a Constituição Francesa de 1958, referente ao momento de sua elaboração e a proximidade do tratamento normativo da alteração constitucional, ditado pelos artigos 138 e 139 da Constituição Italiana de 1947, com aqueles adotados pelas Constituições brasileira de 1988 e francesa de 1958.

16.2. A Constituição Italiana vigente é um significativo exemplo do modelo de constitucionalismo do imediato pós-Segunda Guerra: configura-se como uma constituição rígida, com uma detalhada declaração de direitos; estabelece um sistema de controle de constitucionalidade das leis; estrutura uma moldura para um sistema institucional descentralizado; prevê fortes garantias destinadas a promover e resguardar a independência do Poder Judiciário; e busca assegurar uma combinação de elementos de democracia direta e de democracia representativa. 
16.3. Desde primeiro de janeiro de 1948, um período compreendendo dezessete legislaturas, o precedimento estabelecido pelo artigo 138 foi utilizado para aprovar trinta e nove modificações de caráter constitucional - as chamadas leggi costituzionali - das quais apenas quinze emendaram propriamente o texto constitucional. As restantes vinte e quatro leis constitucionais foram adotadas principalmente para regulamentar certas matérias reservadas constitucionalmente como sendo de alteração exclusiva por legge costituzionale, sem modificar, contudo, o texto constitucional, tratando, em sua maior parte, de aspectos da autonomia das regiões administrativas italianas.

16.4. Das quinze emendas constitucionais italianas - Leggi Costittuzionali que alteraram textualmente a Constituição de 1947, apenas a mais recente delas, a Lei Constitucional n. 1, de 20 de abril de 2012, que instituiu o princípio do orçamento equilibrado, não modificou tema considerado materialmente constitucional. Todas as demais quatorze leis constitucionais afetaram a constituição em sentido material.

17.1. A análise comparativa das manifestações dos poderes constituintes reformadores brasileiro, francês e italiano permite concluir que a numericamente mais elevada taxa de emendamento relativamente à Constituição Brasileira de 1988, comparativamente com as Constituições Francesa de 1958 e Italiana de 1947, contrasta com o significativamente menor índice de mudanças no conteúdo material da Constituição Brasileira, sobretudo se forem consideradas apenas as emendas que alteraram substancialmente o sistema constitucional de cada um dos países objeto de comparação.

18. A estabilidade de uma constituição repousa sobretudo na consonância com a ideia de direito que prevalece na comunidade. Por isso, a mudança constitucional por meio das emendas deve ser vista mais como um processo cumulativo e menos como transformações levadas a efeito desarrazoada e repentinamente. A permanência e a mudança constitucional ligam-se às noções de "senso do possível e sentido da evolução"738, em meio a um processo inacabado, lento e gradativo de construção do Estado Democrático de Direito. Assim, se a Constituição brasileira de 1988 chegar aos seus cinquenta anos, e tiver sido objeto de cento e cinquenta ou de duzentas emendas, e estas tiverem aperfeiçoado o sistema constitucional brasileiro, o número, em si, não será motivo de inquietação - e sequer será passível das críticas superficiais que se costuma fazer a esse respeito.

\footnotetext{
${ }^{738}$ FERREIRA FILHO, Manoel Gonçalves. Ideias para a nova constituição brasileira. São Paulo: Saraiva, 1987 , p. 36.
} 
19. Uma ressalva, contudo, deve ser feita: é preciso ter sempre a consciência de que, sozinhas, as leis constitucionais não podem resolver imediatamente todos os problemas da sociedade. Muitas vezes os problemas jurídicos e políticos que mais afetam a vida das pessoas estão mais associados à deficiente concretização normativo-jurídica do texto constitucional existente, ou, em outras palavras, associam-se mais com a falta das condições conjunturais para a efetivação dos ideais democráticos constitucionalizados, do que propriamente com os dispositivos constitucionais em si.

20. Todas essas observações permitem vislumbrar que a compreensão do poder constituinte a partir de uma perspectiva propositiva, à luz do Direito Comparado, enseja reflexões sobre as condições ideais para o exercício da tarefa de elaborar as constituições, a partir de um determinado modelo de Estado e de sociedade. O poder constituinte reformador parece - ou, pelo menos, deveria - se pautar por uma busca constante de um equilíbrio entre os interesses permanentes e os interesses momentâneos de uma determinada sociedade. Em razão disso, os processos de modificação constitucional devem ser empreendidos observando-se os preceitos da justiça social e da democracia. 


\section{REFERÊNCIAS BIBLIOGRÁFICAS}

AMARAL JÚNIOR, José Levi Mello do. "20 anos da Constituição Brasileira de 1998: A Constituição foi capaz de limitar o poder?” In: MORAES, Alexandre de (Coord.). Os 20 anos da Constituição da República Federativa do Brasil. São Paulo: Atlas, 2009, p. 125-137.

. "Controle de constitucionalidade evolução brasileira determinada pela falta do stare decisis". Revista dos Tribunais, v. 101, n. 920, jun-2012, p. 133-149.

ANCKAR, Dag. "Democracy and Constitutional Endurance". Taiwan Journal of Democracy, v. 10, n. 1, July 2014, p. 23-41.

ANZON, Adele. "Limiti sostanziali della riforma e scindibilità del texto della Costituzione". Rivista di Diritto Costituzionale. Torino: G. Giappichelli, 1998, p. 169-186.

AYRES BRITTO, Carlos. “O Regime Jurídico das Emendas à Constituição”. Tese de Doutorado apresentada à Faculdade de Direito da Pontifícia Universidade Católica de São Paulo, 1999.

BARBALHO, João. Constituição Federal Brasileira. Commentarios. 2. ed. Rio de Janeiro: F. Briguiet e Cia, 1924.

BARBERA, Augusto; MORTATI, Costantino; GIUFRRÉ, Guido. Una e indivisibile. Milano: Giuffrè, 2007.

BARBOSA, Ruy. Commentarios á Constituição Federal Brasileira. v.6, São Paulo: Saraiva, 1934. 
BARROSO, Luís Roberto. Interpretação e aplicação da Constituição. 5. ed. São Paulo: Saraiva, 2003.

BARTOLE, Sergio. "Attuazione e attualità della Costituzione, il ruolo dell' interpretazione". BRUNELlI, Giuditta; CAZZETTA, Giovanni. (Org.) Dalla Costituzione 'inattuata' alla costituzione 'inattuale'? Potere costituente e riforme costituzionali nell'Italia repubblicana. Milano: Giuffrè, 2013, p. 403-428.

BASTID, Paul. Sieyès et sa pensée. Paris: Hachette, 1939.

BASTOS, Celso Ribeiro. Curso de Direito Constitucional. 21. ed. São Paulo: Saraiva, 1999.

BERNSTEIN, Richard. B.; AGEL, Jerome. Amending Constitution: if we love the Constitution so much, why do we keep trying to change it? Lawrence: University Press of Kansas, 1993.

BIGAUT, Christian. Le réformisme constitutionnel en France: 1789-2000. Paris: Documentation Française, 2000.

BIN, Roberto. "Le riforme costituzionale: un "mito" fuorviante". Forum di Quaderni Costituzionali, 17 aprile 2004.

; PITRUZZELlA, Giovanni. Diritto Costituzionale. 11. ed. Torino: G. Giappichelli, 2010.

BISCARETTI DI RUFFIA, Paolo. Introducción al derecho constitucional comparado. México: Fondo de Cultura Económica, 1996. 
BONAVIDES, Paulo. Curso de Direito Constitucional. 19. ed. São Paulo: Malheiros, 2006.

BOYRON, Sophie. "France". In: OLIVER, Dawn; FUSARO, Carlo. How constitutions change. A comparative study. Oxford and Portland: Hart Publishing, 2013, p. 115-142.

BRITO, Miguel Nogueira de. A Constituição Constituinte: ensaio sobre o Poder de Revisão da Constituição. Coimbra: Coimbra Editora, 2000.

BRUNELLI, Giuditta. "Potere costituente e riforme costituzionali nell'Italia Repubblicana". BRUNELLI, Giuditta; CAZZETTA, Giovanni. (Org.) Dalla Costituzione 'inattuata' alla costituzione 'inattuale'? Potere costituente e riforme costituzionali nell'Italia repubblicana. Milano: Giuffrè, 2013, p. 1-22.

BRYCE, James. Constituciones flexibles y constitutiones rígidas. Madrid: Centro de Estudios Constitucionales, 1998.

BURDEAU. Georges. Traité de Science Politique. Paris: Librarie Génerale de Droit et Jurisprudence, 1966.

CÂMARA DOS DEPUTADOS. Anais do Congresso Constituinte da República. v. III, 2. ed. Rio de Janeiro: Imprensa Nacional, 1926, p. 873-874.

CAMPOS, Juliana Cristine Campos. "Nomogênese e Poder Constituinte: fundamentação racional e a legitimidade democrática da norma constitucional”. Tese de Doutoramento apresentada à Faculdade de Direito da Universidade de São Paulo, 2013.

CANOTILHO, José Joaquim Gomes. Direito Constitucional e Teoria da Constituição. 7. ed. Coimbra: Almedina, 2003. 
- “O Processo Especificamente Estruturante: poder constituinte e pacto fundador”. In: Direito Constitucional. 6. ed. Coimbra: Almedina, 1993, p. 87-124.

CASTRO, Araújo. A Constituição de 1937. 2. ed. Rio de Janeiro: Freitas Bastos, 1941.

CASTRO NUNES. A Jornada Revisionista: os rumos, as ideias, o ambiente. Estudo crítico da Constituição em torno da tese "Da necessidade ou conveniência da revisão ou da emenda da Constituição Federal”. Rio de Janeiro: Pap. Almeida Marques \& C., 1924.

CAVALCANTI, Themistocles. “A Constituição de 1967”. Revista Eleitoral da Guanabara. a. 1, n. 1, 1968, p. 85-106.

CAZZETTA, Giovanni. Premessa: dalla Costituzione 'inattuata' alla Costituzione 'inattuale'? BRUNELLI, Giuditta; CAZZETTA, Giovanni. (Org.) Dalla Costituzione 'inattuata' alla costituzione 'inattuale'? Potere costituente e riforme costituzionali nell'Italia repubblicana. Milano: Giuffrè, 2013, v-vii.

COELHO, João G. Lucas; OLIVEIRA, Antonio C. Nantes. A nova Constituição: avaliação do texto e perfil dos constituintes. Rio de Janeiro: Inesc/Revan: 1989, p. 20.

CONSTANTINESCO, Leontin-Jean. Tratado de Direito Comparado: introdução ao Direito Comparado. [Trad. Maria Cristina de Cicco]. Rio de Janeiro: Renovar, 1998.

CONTIADES, Xenophon. "Constitutional change engineering” In: Engineering Constitutional Change: A Comparative Perspective on Europe, Canada and USA. London and New York: Routledge, 2012, p. 1-6. 
. FOTIADOU, Alkmene. "The determinants of constitutional amendability: amendment models or amendment culture?” European Constitutional Law Review, a. 12, n. 1, 2016, p. 192-211.

COUTO, Cláudio Gonçalves; ARANTES, Rogério Bastos. Constituição, governo e democracia no Brasil. In: Revista Brasileira de Ciências Sociais, v. 21, n. 61, Junho de 2006.

CORRÊA, Oscar Dias. “A Constituição brasileira é verdadeira colcha de retalhos”. Revista Jurídica LEMI/Caderno Jornalístico. Belo Horizonte: Lemi, outubro de 1978, p. 3-16.

CRISAFULLI, Vezio; PALADIN, Livio; BARTOLE, Sergio; BIN, Roberto. Commentario breve alla Costituzione. 2. ed. Padova: Cedam, 2008.

DANTAS, Ivo. Direito Constitucional Comparado. v. 1. Teoria do direito comparado. 2. ed. Rio de Janeiro: Renovar, 2006.

DAVID, René. Os grandes Sistemas do Direito Contemporâneo. [Tradução de Hermínio A. Carvalho]. 4. ed. São Paulo: Martins Fontes, 2002.

DE PLÁCIDO E SILVA, Oscar Joseph. Vocabulário Jurídico. 20. ed. Forense: Rio de Janeiro, 2002, p. 208.

DI DONATO, Francesco. "La revisione costituzionale in una prospettiva storicoistituzionale. Il problema del mutamento giuridico in relazione al mutamento sociale e culturale”. In: GAMBINO, Silvio; D’IGNAZIO, Guerino. La revisione costituzionale e i suoi limiti. Fra teoria costituzionale, diritto interno, esperienze straniere. Milano: Giuffrè, 2007, p. 555-578. 
DICEY, Albert Venn. Introduction to the study of the law and the constitution. London: Macmillan, 1961.

DIMOULIS, Dimitri (Org). Resiliência constitucional: compromisso maximizador, consensualismo político e desenvolvimento gradual. São Paulo: Direito GV, 2013.

DIXON, Rosalind. "Constitutional Amendment Rules: A Comparative Perspective”. The University of Chicago Law School. Public Law and Legal Theory Working Papers. n. 347, The University of Chicago Law School, May, 2011.

; LANDAU, David. Transnational constitutionalism and a limited doctrine of unconstitutional constitutional amendment. International Journal of Constitutional Law, 2015, v. 13, n. 3, p. 606-638.

DORSEN, Norman; ROSENFELD, Michel; SAJÓ, András; BAER, Susanne. Comparative Constitutionalism: Cases and Materials. St. Paul: Thomson West Group, 2003.

DUARTE NETO, José. "Rigidez e estabilidade constitucional. Estudo da organização constitucional brasileira". Tese de Doutoramento apresentada à Faculdade de Direito da Universidade de São Paulo, 2009.

DUVERGER, Maurice. Ciência Política. Teoria e Método. 2. ed. [Trad. de Heloísa de Castro Lima]. Rio de Janeiro: Zahar Editores, 1976.

ELKINS, Zachary; GINSBURG, Thomas; MELTON, James. The endurance of national constitutions. New York: Cambridge, 2009. 
; GINSBURG, Thomas; MELTON, James. The lifespan of written constitutions. Article prepared for delivery at the workshop "The diffusion of policies and institutions”. ECPR Joint Sessions, Nicosia, Cyprus 25-30 April 2006.

ELSTER, Jon. “Constitutionalism in Eastern Europe: an introduction”. University of Chicago Law Review, 58, 1991, p. 447-482.

ELSTER, Jon. Ulysses and the Syren: Studies on Rationality and Irrationality. Cambridge: Cambridge University Press, 1984.

FAVOREU, Louis. Droit constitutionnel. 13. ed. Paris: Dalloz, 2010. ; PHILIPPE, Loic. Les grandes décisions du Conseil Constitutionnel. 6 ed. Paris: Sirey, 1991.

FERRAZ, Anna Cândida Cunha. Mutação, reforma e revisão das normas constitucionais. In: Cadernos de Direito Constitucional e Ciência Política. Ano II, n. 5, out./dez. 93, p. 15.

. Processos informais de mudança da Constituição: mutações constitucionais e mutações inconstitucionais. São Paulo: Max Limonad, 1986.

FERRAZ JUNIOR, Tercio Sampaio. Constituinte: Assembléia, Processo, Poder. 2.ed. São Paulo: Revista dos Tribunais, 1986.

FERREIRA, Pinto. Curso de Direito Constitucional. 8.ed. São Paulo: Saraiva, 1996. 
FERREIRA FILHO, Manoel Gonçalves. A reconstrução da democracia. São Paulo: Saraiva, 1979.

. Aspectos do Direito Constitucional Contemporâneo. 2. ed. São Paulo: Saraiva, 2009.

. Comentários à Constituição Brasileira de 1988. 3. ed. São Paulo: Saraiva, 2000.

. Curso de Direito Constitucional. 37. ed. São Paulo: Saraiva, 2011.

. Direito Constitucional Comparado: I. O Poder Constituinte. São Paulo: Editora da Universidade de São Paulo, 1974.

. Do Processo Legislativo. 5. ed. São Paulo: Saraiva, 2002.

- Estabilidade e continuidade da Constituição. In: Idéias para a nova Constituição brasileira. São Paulo: Saraiva, 1987.

. Estado de Direito e Constituição. 4. ed. São Paulo: Saraiva, 2007.

. Poder Constituinte. 6. ed. São Paulo: Saraiva, 2014.

. Princípios Fundamentais do Direito Constitucional. 2. ed. São Paulo: Saraiva, 2010. 
FIALEK, Mariangela. "O exercício do poder de reforma na vigência da Constituição de 1988”. Dissertação de Mestrado apresentada à Faculdade de Direito da Universidade de São Paulo, 2006.

FIORAVANTI, Maurizio. "La trasformazione costituzionale". In: BRUNELLI, Giuditta; CAZZETTA, Giovanni. Dalla Costituzione 'inattuata' alla costituzione 'inattuale'? Potere costituente e riforme costituzionali nell'Italia repubblicana. Milano: Giuffrè, 2013, p. 355-363.

FIUZA, Ricardo Arnaldo Malheiros. Direito Constitucional Comparado. 5. ed. Belo Horizonte: Del Rey, 2013.

FRANCISCO, José Carlos. Emendas Constitucionais e limites flexíveis. Rio de Janeiro: Forense, 2003.

FUCK, Luciano Felício. “STF também é responsável pelo número de emendas constitucionais". Análise Constitucional. Consultor Jurídico. São Paulo, 7 nov. 2016.

FUSARO, Carlo. “Italy”. In: OLIVER, Dawn; FUSARO, Carlo. How constitutions change. A comparative study. Oxford and Portland: Hart Publishing, 2013, p. 211-234.

GALLO, Franco. "La revisione costituzionale ed i suoi limiti”. Ricerche Giuridiche, v. 2, n. 2, Venezia: Edizione Ca'Foscari, 2013, p. 463-474.

GAMBINO, Silvio. "La riforma costituzionale in Italia: chiavi di analisi di un insuccesso prevedibile". Revue Juridique sur l'Evolution de la Nation et de l'État en Europe. n. 2, Nancy, 1999, p. 231-276.

GARCIA-PELAYO, Manuel. Derecho constitucional comparado. 7. ed. Madrid: Revista de Occidente, 1964. 
GENEVOIS, Bruno. "Les limites d'ordre juridique à l'intervention du pouvoir constituant". Revue Française de Droit Administratif. v. 14, n. 15, Paris, 1998, p. 909-921.

GICQUEL, Jean. Droit constitutionnel et institutions politiques. 10 ed. Paris: Montchrestien, 1989.

GINSBURG, Tom; DIXON, Rosalind. "Comparative Constitutional Law: Introduction”. Public Law and Legal Theory Working Papers. n. 362. The University of Chicago Law School, September 2011.

; ELKINS, Zachary; BLOUNT, Justin. "Does the process of constitutionmaking matter?” The Annual Review of Law and Social Science, July 2009.

; MELTON, James. "Does the constitutional amendment rule matter at all? Amendment cultures and the challenges of measuring amendment difficulty. Public Law and Legal Theory Working Papers. n. 472. The University of Chicago Law School, May 2014.

GÓMEZ, Itziar. "La revisión siempre abierta de la V.a República francesa a través de sus reformas constitucionales”. In: Cuadernos de Derecho Público, n. 34-35, 2008, p. 225246.

GRIMM, Dieter. Constituição e Política. [Tradução de Geraldo de Carvalho, coordenação e supervisão de Luiz Moreira]. Belo Horizonte: Del Rey, 2006.

. Types of Constitution. In: ROSENFELD, Michel; SAJÓ, Andras (Ed.) The Oxford Handbook of Comparative Constitutional Law. Oxford University Press, 2012, p. $98-132$. 
GROPPI, Tania. "Constitutional Revision in Italy: a Marginal Instrument for Constitutional Change". In: CONTIADES, Xenophon. Engineering Constitutional Change: A Comparative Perspective on Europe, Canada and USA. London and New York: Routledge, 2012, p. 203-228.

HAMON, Francis; TROPER, Michel; BURDEAU, Georges. Droit Constitutionnel. [Tradução de Carlos Souza] 27. ed. Barueri: Manole, 2005.

HESSE, Konrad. A Força Normativa da Constituição. [Tradução de Gilmar Ferreira Mendes]. Porto Alegre: Sérgio Antônio Fabris, 1991.

HIRSCHL, Ran. From comparative constitutional law to comparative constitutional studies. International Journal of Constitutional Law, 2013, v. 11, n. 1, p. 1-12.

HOLANDA FERREIRA, Aurélio Buarque de. Novo Dicionário da Língua Portuguesa. 2. ed. Nova Fronteira: 1986, p. 460.

HOLMES, Stephen. "Precommitment and the paradox of democracy". In: ELSTER, Jon; SlAGSTAD, Rune. Constitutionalism and Democracy. Cambridge: Cambridge University Press, 1988, p. 195-240.

HORBACH, Carlos Bastide. "Discutindo o cânone constitucional brasileiro". Análise Constitucional. Consultor Jurídico. São Paulo, 6 abr. 2014.

HORTA, Raul Machado. "Permanência e mudança na Constituição". Revista de Informação Legislativa. v. 29, n. 115, Brasília: Senado Federal, jul./set. 1992, p. 5-26.

JACKSON, Vicki C. Comparative Constitutional Law: methodologies, p. 54-74. 
JUNQUEIRA, Maria Olívia Pessoni. "Discurso e política constitucional: a reforma constitucional na doutrina brasileira da Primeira República”. Dissertação de Mestrado apresentada à Faculdade de Direito da Universidade de São Paulo, 2015.

KNIGHT, Jack. "Institutionalizing constitutional interpretation". In: FEREJOHN, John; RAKOVE, Jack; RILEY, Jonathan. Constitutional culture and democratic rule. Cambridge: Cambridge University Press, 2001, p. 361-392.

LEVINSON, Sanford. Designing an Amendment Process. In: FEREJOHN, John; RAKOVE, Jack; RILEY, Jonathan. Constitutional culture and democratic rule. Cambridge: Cambridge University Press, 2001, p. 271-287.

. "How many times has the United States Constitution been amended? In: - (Org.) Responding to imperfection: The theory and practice of constitutional amendment. New Jersey: Princeton University Press, 1995, p. 13-36.

LOEWENSTEIN, Karl. Teoría de la Constitución. 2. ed. Barcelona: Ariel, 1979.

LOPES, Mauricio Antonio Ribeiro. Poder Constituinte Reformador: limites e possibilidades da revisão constitucional brasileira. São Paulo: Revista dos Tribunais, 1993.

LOSANO, Mario G. Os Grandes Sistemas Jurídicos: Introdução aos Sistemas jurídicos europeus e extra-europeus. [Tradução de Marcela Varejão e Silvana Cobucci Leite]. São Paulo: Martins Fontes, 2007.

LUTZ, Donald S. "Toward a Theory of Constitutional Amendment". In: LEVINSON, Sanford. (Org.) Responding to imperfection: The theory and practice of constitutional amendment. New Jersey: Princeton University Press, 1995, p. 237-274. 
MAIOLINO, Eurico Zecchin. "Limitações ao poder de reforma constitucional na Constituição Federal de 1988”. Dissertação de Mestrado apresentada à Faculdade de Direito da Universidade de São Paulo, 2011.

MASTOR, Wanda; ICHER, L. "Constitutional amendment in France”. In: CONTIADES, Xenophon. Engineering Constitutional Change: A Comparative Perspective on Europe, Canada and USA. London/New York: Routledge, 2012, p. 115-124.

MCILWAIN, Charles Howard. Constitutionalism. Ancient and Modern. Ithaca, New York, Cornell University Press, 1947.

MELO, Marcus André. "Mudança constitucional no Brasil. Dos debates sobre regras de emendamento na constituinte à 'megapolítica"'. Novos Estudos, v. 97, CEBRAP, 2013, p. 187-206.

MENDES, Conrado Hübner. Judicial review of constitutional amendments in the Brazilian Supreme Court. In: Florida Journal of Intern. Law, v. 17, n. 3, Dec. 2005, p. 449-461.

MENDES, Gilmar Ferreira. BRANCO. Paulo Gonet. Curso de Direito Constitucional. 7. ed. São Paulo: Saraiva, 2012.

MIRANDA, Jorge. Manual de Direito Constitucional. Tomo II. 6. ed. Coimbra: Coimbra Editora, 2007.

. "Sobre o Direito Constitucional Comparado". Revista de Direito Constitucional e Internacional. a. 14, n. 55, abr.-jun. 2006, p. 243-260.

. Teoria do Estado e da Constituição. Rio de Janeiro: Forense, 2002, p. 395. 
MORABITO, Marcel. Histoire constitutionnelle de la France de 1789 à nos jours. 13. ed. Paris: Montchrestien, 2014.

MORAES, Alexandre de. Direito Constitucional. 30 ed. São Paulo: Atlas, 2014.

MOREIRA, Vital. Constituição e democracia na experiência portuguesa. In: MAUÉS, Antonio G. Moreira (Org.). Constituição e democracia. São Paulo: Max Limonad, 2001, p. 261-290.

MORTATI, Costantino. "La costituzione in generale". In: BARBERA, Augusto; MORTATI, Costantino; GIUFRRÉ, Guido. Una e indivisibile. Milano: Giuffrè, 2007, p. 61-236.

NEGRETTO, Gabriel L. "The durability of Constitutions in changing environments: explaining constitutional replacements in Latin America”. Kellogg Institute Working Paper n. 350, August 2008.

NEVES, Marcelo. A Constituição Simbólica. São Paulo: Martins Fontes, 2007.

NORONHA, Lincoln Narcelio Thomaz. "Em direção a uma teoria de emendamento constitucional: críticas metodológicas e perspectivas de avanço sobre a mudança constitucional". Anais eletrônicos de Política, Direito e Judiciário do IX Encontro da Associação Brasileira de Ciência Política. Brasília, 4 a 7 de agosto de 2014.

OKLOPCIC, Zoran. "The paradox of constitutionalism: constituent power and constitutional form. Book Review". International Journal of Constitutional Law, 2008, v. 6, n. 2, p. 358-370.

OLIVER, Dawn; FUSARO, Carlo. How constitutions change. A comparative study. Oxford and Portland: Hart Publishing, 2013.

ONIDA, Valerio. "Il 'mito' delle riforme costituzionale". Rivista Bimistrale di Cultura e di Politica. v. 1. Bologna: Il Mulino, 2004, pp. 15-29. 
PAINE, Thomas. Direitos do homem: um dos clássicos da democracia moderna. [Trad. de Edson Bini]. Bauru: Edipro, 2005.

PHILIPPE, Xavier. "France: the amendment of the French Constitution 'on the descentralized organization of the Republic"'. International Journal of Constitutional Law, 2004, v. 2, n. 4, p. 691-722.

PICARD, Étienne. "Les révisions constitutionnelles en France". Revista de Derecho Político, n. 37, Madrid, 1992, p. 335-372.

PINTO, Almir Pazzianoto. A Crise Constitucional. In: RODRIGUES DO AMARAL, Antonio Carlos; ROSAS, Roberto; VELlOSO, Carlos Mário da Silva. Princípios Constitucionais Fundamentais: estudos em homenagem ao professor Ives Gandra da Silva Martins. São Paulo: Lex, 2005, p. 73-83.

PINTO FERREIRA, Luís. Curso de Direito Constitucional. 8. ed. São Paulo: Saraiva, 1996.

POMBENI, Paolo. "Ma le riforme costituzionali sono davvero un 'mito"'. Forum di Quaderni Costituzionali, 10 gennaio 2004.

PONTES DE MIRANDA, Francisco Cavalcante. Comentários à Constituição de 1967. Tomo III (Arts. 34-112). São Paulo: RT, 1967, p. 128-149. . Comentários à Constituição da República dos Estados Unidos do Brasil. Tomo I. Rio de Janeiro: Guanabara Waissman Koogan, 1936.

. Comentários à Constituição de 1946. Tomo I (Arts. $1^{\circ}$ a 5\%). 3. ed. Rio de Janeiro: Borsoi, 1960. 
PREUSS, Ulrich K. "The exercise of constituent power in Central and Eastern Europe". In: WALKER, Neil; LOUGHLIN, Martin. The Paradox of Constitutionalism: Constituent Power and Constitutional Form. Oxford: Oxford University Press, 2007, p. 212.

RANGEL, Henrique; BOLONHA, Carlos. "Governabilidade e capacidade para emendar: o Poder Executivo e as Emendas Constitucionais". In: SANTOS, Rogério; GABARDO, Emerson; SANTIN, Janaina (Coord.) Teoria do Estado e da Constituição. XXII Encontro Nacional do CONPEDI. Florianópolis: Funjab, 2013, p. 365-391.

ROBERTS, A. The politics of constitutional amendment in postcommunist Europe. Constitutional Political Economy. v. 20, n. 2, 2009, p. 99-117.

ROCHA, Cármen Lúcia Antunes. "Constituição e mudança constitucional: limites ao exercício do poder de reforma constitucional". Revista de Informação Legislativa, v. 30, n. 120, out./dez. 1993, p. 159-186.

ROSENFELD, Michel; SAJÓ, Andras (Ed.) The Oxford Handbook of Comparative Constitutional Law. Oxford University Press, 2012.

ROZNAI, Yaniv. "Unamendability and the Genetic Code of the Constitution". New York University Public Law and Legal Theory Working Papers. Paper 514, 2015.

SAJÓ, András. Limiting Government: An Introducion to Constitutionalism. Budapest: Central European University, 1999.

SALDANHA, Nelson. O Poder Constituinte. São Paulo: Revista dos Tribunais, 1986.

SAMPAIO, Nelson de Souza. O Poder de Reforma Constitucional. Salvador: Progresso, 1954. 
SÁNCHEZ NAVARRO, Ángel. "La reforma constitucional en Francia". Teoría y Realidad Constitucional, n. 1. Madrid, 1998, p. 205-213.

SARLET, Ingo W; BRANDÃO, Rodrigo. “Comentários ao artigo 60. CANOTILHO, J. J. Gomes; MENDES, Gilmar F.; SARLET, Ingo W. STRECK, Lenio L. (Coord.). Comentários à Constituição do Brasil. São Paulo: Saraiva/Almedina, 2013.

; MARINONI, Luiz Guilherme; MITIDIERO, Daniel. Curso de Direito Constitucional. 5. ed. São Paulo: Saraiva, 2016.

SARTORI, Giovanni. Ingenería Constitucional Comparada: una investigación de estructuras, incentivos y resultados. [Tradução de Roberto Reyes Mazzoni]: México: Fondo de Cultura Económica, 1996.

SCHMITT, Carl. Teoría de la Constitución. [Tradução para o espanhol por Francisco Ayala]. 1. ed. 4. reimpr. Madrid: Alianza Editorial, 2003.

SCHLESINGER, Rudolf B; BAADE, Hans W.; HERZOG, Peter E. Comparative law: cases, text, materials. 6. ed. New York : Foundation Press, 1998.

SIEYÈS, Emmanuel. Qu'est-ce que le tiers état? Genève: Droz, 1970.

SILVA, José Afonso da. Curso de Direito Constitucional Positivo. 26. ed. São Paulo: Malheiros, 2006.

. "Direito Constitucional Comparado e Reforma do Estado". In: BONAVIDES, Paulo; LIMA, Francisco G. de; BEDÊ, Fayga. Constituição e Democracia: Estudos em homenagem ao Professor Gomes Canotilho. São Paulo: Malheiros, 2006, p. 336-362. 
. Poder Constituinte e Poder Popular: estudos sobre a Constituição. 1. ed. São

Paulo: Malheiros, 2002.

. Um pouco de Direito Constitucional Comparado: três projetos de Constituição.

São Paulo: Malheiros, 2009.

SILVA, Virgílio Afonso da. “A Fossilised Constitution?”. Ratio Juris, v. 17, issue 4, 2004, p. $454-473$.

- "Ulisses, as sereias e o poder constituinte derivado: sobre a inconstitucionalidade da dupla revisão e da alteração no quórum de 3/5 para aprovação de emendas constitucionais". Revista de Direito Administrativo, n. 226, 2001, p. 11-36.

SOUZA, Celina. Instituições e mudanças: reformas da Constituição de 1988, federalismo e políticas públicas. In: HOCHMAN, Gilberto; FARIA, Carlos Aurélio Pimenta de (Org.). Federalismo e políticas públicas no Brasil. Rio de Janeiro: Fiocruz, 2013. p. 91118.

. "Regras e contexto: as reformas da Constituição de 1988". Dados. Revista de Ciências Sociais, v. 51, n. 4, Rio de Janeiro, 2008, p. 791-823.

SINGH, Mahendra Pal. "India". In: How constitutions change. A comparative study. Oxford and Portland: Hart Publishing, 2013, p. 169-190

SRIPATI, Vijayashri; THIRUVENGADAM, Arun K. India: Constitutional amendment making the right to education a Fundamental Right. International Journal of Constitutional Law, 2004, v. 2, n. 1, p. 148-158. 
STERN, Klaus. Derecho del Estado de la República Federal Alemana. [Tradução de Javier Pérez-Royo e Pedro Cruz Villalón]. Madrid: Centro de Estudios Constitucionales, 1987

SUNSTEIN, Cass R. A constitution of many minds. Why the Founding Document doesn't mean what it meant before. Princeton: Princeton University Press, 2009.

; HOLMES, Stephen. "The politics of constitutional revision in Eastern Europe”. In: LEVINSON, Sanford. Responding to imperfection: The theory and practice of constitutional amendment. New Jersey: Princeton University Press, 1995, p. 275-306.

TEMER, Michel. Elementos de direito constitucional. 23. ed. São Paulo: Malheiros, 2010.

TROPER, Michel; HAMON, Francis. BURDEAU, Georges. Direito constitucional. 27. ed. [Tradução de Carlos Souza]. Barueri: Manole, 2005.

TUSHNET, Mark. Advanced Introduction to Comparative Constitutional Law. Cheltenham/Northampton: Edward Elgar, 2014.

; “Comparative Constitutional Law”. In: ZIMMERMANN, Reinhard, REIMANN, Mathias. The Oxford handbook of comparative law. Oxford: Oxford University Press, 2008, p. 1225-1257.

VEGA, Pedro. La Reforma Constitucional y la Problematica del Poder Constituyente. Madrid: Editorial Tecnos, 1985.

VERGOTTINI, Giuseppe de. Diritto Costituzionale Comparato. 5. ed. Pádua: Cedam, 1999. 
VICTOR, Sérgio Antônio Ferreira. Diálogo institucional e controle de constitucionalidade: debate entre o STF e o Congresso Nacional. São Paulo: Saraiva, 2015.

VILE, John R. "The case against implicit limits on the constitutional amending process". In: LEVINSON, Sanford. Responding to imperfection: The theory and practice of constitutional amendment. New Jersey: Princeton University Press, 1995, p. 191-214.

WALDRON, Jeremy. "Precommitment and disagreement". In: ALEXANDER, Larry. Constitutionalism: philosophical foundations. Cambridge: Cambridge University Press, 1998, p. 271-299.

WANG, Daniel. "Introdução". . (Org.). Constituição e Política na Democracia: aproximações entre Direito e Ciência Política. São Paulo: Marcial Pons, 2013, p. 1117.

ZAGREBELSKY, Gustavo. "Estado constitucional”. [Tradução de Carlos Bastide Horbach e José Levi Mello do Amaral Júnior]. HORBARCH, Carlos Bastide; ALMEIDA, Fernando Dias Menezes; AMARAL JUNIOR, José Levi Mello do; LEAL, Roger Stiefelmann. Direito Constitucional, Estado de Direito e Democracia: homenagem ao Prof. Manoel Gonçalves Ferreira Filho. São Paulo: Quartier Latin, 2011, p. 291-315.

ZWEIGERT, Konrad; KÖTZ, Hein. Introduction to Comparative Law. 3. ed. New York: Oxford University Press, 1998. 